\title{
Eddy-Resolving Simulation of Plankton Ecosystem Dynamics in the California Current System
}

\author{
Nicolas Gruber ${ }^{\mathrm{a}, 1}$ Hartmut Frenzel ${ }^{\text {a }}$ Scott C. Doney ${ }^{\mathrm{d}}$ \\ Patrick Marchesiello ${ }^{\text {e James C. McWilliams }}{ }^{\text {a John R. Moisan }}{ }^{\mathrm{c}}$ \\ John J. Oram ${ }^{\mathrm{b}, 2}$ Gian-Kasper Plattner ${ }^{\mathrm{a}, 3}$ \\ Keith D. Stolzenbach ${ }^{\mathrm{b}}$ \\ ${ }^{a}$ Institute of Geophysics and Planetary Physics (IGPP) $\&$ Department of \\ Atmospheric and Oceanic Sciences, University of California at Los Angeles, Los \\ Angeles, CA 90095. \\ ${ }^{\mathrm{b}}$ Civil and Environmental Engineering, University of California at Los Angeles, \\ Los Angeles, CA 90095. \\ ${ }^{\mathrm{c}}$ Laboratory for Hydrospheric Processes, Observational Science Branch, \\ NASA/GSFC Wallops Flight Facility, Wallops Island, VA $2333 \%$. \\ ${ }^{\mathrm{d}}$ Department of Marine Chemistry and Geochemistry, Woods Hole Oceanographic \\ Institution, Woods Hole, MA 02543. \\ e IRD Centre de Bretagne, Plouzane, France.
}

\begin{abstract}
We study the dynamics of the planktonic ecosystem in the coastal upwelling zone within the California Current System using a three-dimensional, eddy-resolving cir-
\end{abstract}

Preprint submitted to Elsevier Science

13 June 2006 
culation model coupled to an ecosystem/biogeochemistry model. The physical model is based on the Regional Oceanic Modeling System (ROMS), configured at a resolution of $15 \mathrm{~km}$ for a domain covering the entire U.S. West Coast, with an embedded child grid covering the central California upwelling region at a resolution of $5 \mathrm{~km}$. The model is forced with monthly mean boundary conditions at the open lateral boundaries as well as at the surface. The ecological/biogeochemical model is nitrogen based, includes single classes for phytoplankton and zooplankton, and considers two detrital pools with different sinking speeds. The model also explicitly simulates a variable chlorophyll-to-carbon ratio. Comparisons of model results with either remote sensing observations (AVHRR, SeaWiFS) or in situ measurements from the CalCOFI program indicate that our model is capable of replicating many of the large-scale, time averaged features of the coastal upwelling system. An exception is the underestimation of the chlorophyll levels in the northern part of the domain, perhaps because of the lack of short-term variations in the forcing from the atmosphere. Another shortcoming is that the modeled thermocline is too diffuse, and that the upward slope of the isolines toward the coast is too small. Detailed time-series comparisons with observations from Monterey Bay reveal similar agreements and discrepancies. We attribute the good agreement between the modeled and observed ecological properties in large part to the accuracy of the physical fields. In turn, many of the discrepancies can be traced back to our use of monthly mean forcing. Analysis of the ecosystem structure and dynamics reveal that the magnitude and pattern of phytoplankton biomass in the nearshore region are determined largely by the balance of growth and zooplankton grazing, while in the offshore region, growth is balanced by mortality. The latter appears to be inconsistent with in situ observations and is a result of our consideration of only one zooplankton size class (mesozooplankton), neglecting the importance of microzooplankton grazing in the offshore region. A comparison of the allocation of nitrogen into the different pools of the ecosystem in the $3-\mathrm{D}$ results with those obtained from a box model config- 
uration of the same ecosystem model reveals that only a few components of the ecosystem reach a local steady-state, i.e. where biological sources and sinks balance each other. The balances for the majority of the components are achieved by local biological source and sink terms balancing the net physical divergence, confirming the importance of the 3-D nature of circulation and mixing in a coastal upwelling system.

Key words: Phytoplankton Dynamics, Nutrient Cycling, Coastal Biogeochemistry, California Current, Upwelling

\section{Introduction}

The continental margins are among the most productive and biogeochemically active environments on Earth. It is estimated that nearly half of the globally integrated oceanic primary production and the bulk of sedimentary carbon burial occurs in this narrow zone (about $300 \mathrm{~km}$ wide), which covers only a few percent of the global ocean area (Walsh, 1991; Smith and Hollibaugh, 1993; Muller-Karger et al., 2005). Relative to plankton dynamics and biogeochemical cycling in the open ocean (e.g. Fasham et al. (2001)), comparatively little is known about the overall role of the continental margins in the global cycling of elements, their natural variability, or their potential responses and feedbacks to global climate change (e.g. Doney (1999) and Liu et al. (2000)).

\footnotetext{
Email address: ngruber@igpp.ucla.edu (Nicolas Gruber).

1 Corresponding author

2 Now at San Francisco Estuary Institute, Oakland, CA 94621.

3 Now at Climate and Environmental Physics, Physics Institute, University of Bern, Bern, Switzerland.
} 
Eastern boundary current (EBC) systems, such as the California, Humboldt, Canary, and Benguela Currents, belong to the most productive coastal environments (Carr, 2002; Carr and Kearns, 2003), providing the base for food webs that support some of the most economically important fisheries. The high rate of formation of organic matter by phytoplankton and the subsequent export of this material into the ocean interior stimulate a very rapid turnover of biologically important elements in these systems (Wollast, 1991, 1998). Among many consequences, this provides a mechanism for taking up inorganic carbon from the near surface ocean and transporting it downward or toward the open ocean as organic carbon, potentially making these systems a sink for atmospheric $\mathrm{CO}_{2}$ (Tsunogai et al., 1999; Thomas et al., 2004).

The high biological productivity in these EBC systems is fueled by the supply of nutrients from upwelling, a result of the prevailing equatorward blowing winds that push the near surface waters offshore through Ekman transport, causing nutrient-rich waters from mid-depths to upwell to the surface. The physical environment of these EBC systems is also characterized by slowly varying longshore currents and often intense meso- and submeso-scale variability. The latter leads to a tight coupling between physical and biological processes, documented most evidently by the strong co-variance of sea surface temperature (SST) and chlorophyll (e.g. Denman and Abbott (1994) and DiGiacomo and Holt (2001)). These observations indicate clearly the important role of physical transports in initiating, sustaining, and dispersing biological production and in determining the associated cycling of elements.

Much effort has been spent on systematic observations of physical, chemical, and biological processes in EBCs, (e.g. Coastal Upwelling Experiment (CUE), Coastal Ocean Dynamics Experiment (CODE), Coastal Ocean Pro- 
cesses (CoOP) in the California Current System), but the often spotty spatial coverage and intermittent sampling make it difficult to determine the pathways of elemental flow through the system and to establish elemental budgets. As a consequence, relatively little is known about the dynamics of elemental cycles in EBC regions and how they shape the magnitude and pattern of biological production.

A relatively recently developed method to address this question is the use of three-dimensional coupled physical-ecological-biogeochemical models. Fasham et al. (1993) and Sarmiento et al. (1993) pioneered this approach by coupling a nitrogen based, single phytoplankton functional group, single zooplankton, bacteria, and detritus model developed by Fasham et al. (1990) to a threedimensional ocean general circulation model (OGCM) of the North Atlantic. They demonstrated that the large-scale distribution of chlorophyll in the North Atlantic can be simulated with a reasonable degree of accuracy. However, detailed comparisons with observations at time-series sites revealed that the model's representation of the underlying processes supplying the nutrients were not as satisfactory. This seminal work spawned a large number of studies, including, more recently, the use of eddy-resolving models (Oschlies and Garçon, 1998; Oschlies, 2001; McGillicuddy et al., 2003) or ecosystem models of substantially higher complexity (Chai et al., 2003; Gregg et al., 2003; Moore et al., 2004; Lima and Doney, 2004).

In contrast to the many efforts of applying such three-dimensional (3-D) coupled physical-ecological-biogeochemical models to open ocean environments, there are fewer studies in coastal environments and EBC systems (see Moisan et al. (2005) for a review). Moisan et al. (1996) were among the first who used a 3-D coupled model in an EBC setting, but their simulation extended 
over a few days only, and therefore permitted investigation of only a limited aspect of the flow of material through the system. Most other existing investigations of biological-physical interactions in EBCs and their impact on ecology and biogeochemistry have used reduced-order physical models, such as onedimensional models (e.g. Moloney and Field (1991)), two-dimensional models (e.g. Walsh (1975), Wroblewski (1977), and Spitz et al. (2003)) or box models with a specified upwelling flux of nutrients (e.g. Olivieri and Chavez (2000); Ianson and Allen (2002)). Such reduced-order physical models have been chosen for their computational efficiency, and the relative ease with which the results can be analyzed.

Over the last two decades, substantial progress has been made in developing three-dimensional physical models covering limited domains (e.g. Princeton Ocean Model (POM) (Blumberg and Mellor, 1987); S-Coordinate Rutgers University Model (SCRUM) (Song and Haidvogel, 1994); Regional Oceanic Modeling System (ROMS) (Shchepetkin and McWilliams, 2005)). Furthermore, computational power and methods have improved dramatically, permitting the study of the dynamics of the coupling between biology, biogeochemistry, and physics in a limited domain at eddy-resolving resolution (e.g. Penven et al. (2001), Slagstad and Wassmann (2001), Spitz et al. (2005) and Koné et al. $(2005))$.

In this study, we address the coupling of ocean physics and planktonic ecosystems using such a computational modeling approach in the context of the California Current System (CCS). Our objectives are (i) to describe the model components and to evaluate the simulated results quantitatively with observations, (ii) to study the impact of the physical-biological coupling on ecosystem structure, with a particular emphasis on the relative abundances of fixed nitro- 
gen in the different pools of the ecosystem. Our modeling approach is based on the coupling of an NPZD-type planktonic ecosystem-biogeochemistry model to a U.S. West Coast configuration of ROMS (Marchesiello et al., 2003). We thereby make use of the embedding capabilities of ROMS, permitting us to simulate this coupling at a fully eddy-resolving resolution of about $5 \mathrm{~km}$ along most of the central California Coast, while resolving the dynamics at about 15 $\mathrm{km}$ resolution for the entire domain from Baja California in the south to the U.S./Canadian border in the north. A characteristic of our simulations is that because of the use of an improved formulation of the lateral boundary conditions, we are able to obtain multi-year equilibrium solutions for both the physical and ecosystem models. We will demonstrate that the model reproduces the observed spatial and temporal variability in the planktonic ecosystems to first order. We will also show that our ecosystem model, by construction, has limited success to simulate simultaneously the highly productive coastal ecosystems and the relatively unproductive offshore ecosystems. As our focus is on biological productivity and the cycling of elements in the coastal environment, we have selected the parameters of the ecological model to represent upwelling ecosystems, accepting the shortcomings of this choice in the offshore regions.

This paper is organized as follows: We first describe the model and its components, and then subject the results to a quantitative evaluation with data based metrics. In the second part, we investigate the model simulated ecosystem structure and its dynamics, first focusing on the individual components, and then assessing how fixed nitrogen is allocated to the individual ecosystem pools as a function of the total fixed nitrogen content of the model. We will use the solution of a mixed-layer box model configuration as a reference. 


\section{Model Description}

The main components of the model are (i) a physical model that simulates the 3-D time-variant flow and mixing of ocean waters, (ii) an ecosystembiogeochemical model that computes the source and sink terms for the reactive biological and chemical components, and (iii) an optical model that computes the vertical penetration of short-wave radiation into the ocean, determining the amount of light available for phytoplankton to grow. We discuss each model component in turn. Further details are given in the online material section.

\subsection{Physical Model}

The physical model we employ is a United States West Coast (USWC) configuration of the Regional Oceanic Modeling System (ROMS) (Marchesiello et al., 2003; Shchepetkin and McWilliams, 2005). We give here only a brief overview of the physical model. The reader interested in more details is referred to Shchepetkin and McWilliams (2005) and Marchesiello et al. (2003).

ROMS solves the primitive equations of flow, and is discretized in horizontal curvilinear coordinates and a generalized terrain-following vertical coordinate ( $\sigma$ coordinate), which is configured to enhance resolution near the sea surface. The prognostic variables are surface elevation, barotropic and baroclinic horizontal velocity components, potential temperature and salinity, and the state variables of the ecosystem-biogeochemical model (see below).

Of particular relevance for the ecosystem-biogeochemistry simulations is that 
vertical mixing in the interior and in the planetary boundary layer is calculated with the non-local, K-Profile Parameterization scheme (KPP: Large et al. (1994)), which performs well in both measurement comparisons and large-domain model solutions (Large and Gent, 1999; Li et al., 2001). Of further relevance are the open boundary conditions, which are formulated as a combination of outward radiation and flow-adaptive nudging toward prescribed external conditions (see Marchesiello et al. (2001)). We also benefit from the embedding capabilities of ROMS (Penven et al., 2006), which we use to more finely resolve the coastal region in the central part of our domain.

In the USWC configuration adopted here, the outer domain extends in latitude from the middle of Baja California $\left(28^{\circ} \mathrm{N}\right)$ to the Canadian Border $\left(48^{\circ} \mathrm{N}\right.$; approximately coincident with the subtropical/subpolar gyre boundary) (see Figure 1). The model therefore spans a domain that is about $2100 \mathrm{~km}$ long and $1300 \mathrm{~km}$ wide, and encompasses the CCS and its most energetic regions. The horizontal grid spacing of the outer grid is about $15 \mathrm{~km}(85 \times 170$ grid points). We embedded a reduced domain model with a resolution of about 5 $\mathrm{km}$ (Figure 1) to more finely resolve the most dynamic region of the CCS. The domain of this child grid is the central California upwelling region and extends from Point Conception $\left(34^{\circ} 35^{\prime} \mathrm{N}\right)$ in the south to approximately the California/Oregon border $\left(41^{\circ} 51^{\prime} \mathrm{N}\right)$ in the north. The child grid covers about $15 \%$ of the parent grid with an offshore extent of about $500 \mathrm{~km}$, and an alongshore extent of about $800 \mathrm{~km}(95 \times 191$ points $)$. The child grid is embedded in a one-way manner within the parent grid, i.e. information about the state of the model is passed from the parent grid to the child grid at each time step, while no such transfer occurs in the opposite direction. Our limited experience with two-way embedding shows relatively little difference between 
one-way and two-way embedding, so that we opted for one-way embedding because of its computational simplicity. Both grids have 20 vertical levels with vertical refinement near the surface to allow for a reasonable representation of the surface boundary layer and the euphotic zone everywhere in the domain. On average, about 8 levels are within the euphotic zone, defined here as the $1 \%$ light level.

\subsection{Ecological-Biogeochemical Model}

The ecological-biogeochemical model is a nitrogen based NPZD model. It consists of a system of seven coupled partial differential equations that govern the time and space distribution of the following non-conservative scalars: nitrate ( $\mathrm{NO}_{3}^{-}$, subsequently denoted as $N_{n}$ to reflect "new" nitrogen, e.g. Dugdale and Goering (1967)), ammonium $\left(\mathrm{NH}_{4}^{+}\right.$, denoted as $N_{r}$ to reflect "regenerated" nitrogen), phytoplankton $(P)$, zooplankton $(Z)$, small $\left(D_{S}\right)$ and large $\left(D_{L}\right)$ detritus, and a dynamic phytoplankton chlorophyll-to-carbon ratio $(\theta)$ (see Figure 2). The state variables represent concentrations of nitrogen within the different pools and have units of mmol $\mathrm{N} \mathrm{m}^{-3}$, except for $\theta$, which has units of $\mathrm{mg}$ Chl-a $(\mathrm{mg} \mathrm{C})^{-1}$ (the latter is converted to per nitrogen units in the model assuming a constant carbon to nitrogen ratio of phytoplankton). The tracer conservation equation for any of the above 7 scalars $B$ is given by:

$$
\frac{\partial B}{\partial t}=\nabla \cdot K \nabla B-\vec{u} \cdot \nabla_{h} B-\left(w+w^{\text {sink }}\right) \frac{\partial B}{\partial z}+J(B)
$$

where $K$ is the eddy kinematic diffusivity tensor, and where $\nabla$ and $\nabla_{h}$ are the 3 -D and horizontal gradient operators, respectively. The symbols $\vec{u}$ and 
$w$ denote the horizontal and vertical velocities of the fluid, respectively, and $w^{\text {sink }}$ is the vertical sinking rate of the biogeochemical components. Sinking affects all particulate pools, except for zooplankton. Finally, $J(B)$ represents the source minus sink term for each biogeochemical scalar, described in detail below.

Structurally, the model builds on a long history of planktonic ecosystem models, starting, among others, with those of Walsh and Dugdale (1971) and Steele (1974) (see Hood and Christian (2006) for a historical overview). Our model is an evolutionary descendent of the ecosystem model of Fasham et al. (1990), but was modified in a number of important ways. First, bacteria were eliminated as an explicitly modeled state variable, and replaced with implicit parameterizations of remineralization processes. Second, dissolved organic nitrogen $(D O N)$ and detrital organic nitrogen were replaced with two pools of detritus, a large one that sinks fast, and a small one that sinks slowly, the latter mimicking DON and fine, slow-sinking particles. The small detrital pool coagulates with phytoplankton, thereby forming large, fast sinking detritus. Third, sinking is modeled explicitly, thereby permitting all state variables to be advected laterally even in the aphotic zone. Finally, a variable chlorophyllto-carbon ratio is considered here. Most of these changes were made to simplify the model and to reduce the number of parameters, while maintaining or improving the model's skill.

The full set of source and sink terms, $J(B)$, for each of the seven biogeochemical model components are written as: 


$$
\begin{aligned}
& J(P)=\mu_{P}^{\max }(T, I) \cdot \gamma\left(N_{n}, N_{r}\right) \cdot P \\
& -g_{Z}^{\text {graz }} Z \frac{P}{K_{P}+P}-\eta_{P}^{\text {mort }} P-k^{\text {coag }} P \cdot\left(P+D_{S}\right) \\
& J(Z)=g_{Z}^{\text {graz }} \beta_{Z}^{\text {assim }} Z \frac{P}{K_{P}+P}-\eta_{Z}^{\text {metab }} Z-\eta_{Z}^{\text {mort }} Z^{2} \\
& J\left(N_{n}\right)=-\mu_{P}^{\max }(T, I) \cdot \gamma\left(N_{n}\right) \cdot P+k^{n i t r}(I) \cdot N_{r} \\
& J\left(N_{r}\right)=-\mu_{P}^{\max }(T, I) \cdot \gamma\left(N_{r}\right) \cdot P-k^{n i t r}(I) \cdot N_{r}+\eta_{Z}^{\text {metab }} Z \\
& +k_{D_{S}}^{r e m i n} D_{S}+k_{D_{L}}^{r e m i n} D_{L} \\
& J\left(D_{S}\right)=g_{Z}^{\text {graz }} \cdot\left(1-\beta_{Z}^{\text {assim }}\right) \cdot\left(1-\Omega_{Z}^{\text {egest }}\right) \cdot Z \frac{P}{K_{P}+P} \\
& +\eta_{P}^{\text {mort }} P+\eta_{Z}^{\text {mort }} \cdot\left(1-\Omega_{Z}^{\text {mort }}\right) Z^{2} \\
& -k^{\text {coag }} D_{S} \cdot\left(P+D_{S}\right)-k_{D_{S}}^{\text {remin }} D_{S} \\
& J\left(D_{L}\right)=g_{Z}^{\text {graz }} \cdot\left(1-\beta_{Z}^{\text {assim }}\right) \Omega_{Z}^{\text {egest }} Z \frac{P}{K_{P}+P} \\
& +\eta_{Z}^{\text {mort }} \Omega_{Z}^{\text {mort }} Z^{2} \\
& +k^{\text {coag }} \cdot\left(P+D_{S}\right)^{2}-k_{D_{L}}^{r e m i n} D_{L} \\
& J(\theta)=\mu_{P}^{\max }(T, I) \cdot \gamma\left(N_{n}, N_{r}\right)\left(\frac{\mu_{P}^{T}(T) \cdot \gamma\left(N_{n}, N_{r}\right) \cdot \theta^{\max }}{\sqrt{\left(\mu_{P}^{T}(T)\right)^{2}+\left(\alpha_{P} I \theta\right)^{2}}}-\theta\right)
\end{aligned}
$$

where symbols with parentheses, such as $\mu_{P}^{\max }(T, I)$ represent functions of the respective variables, while all other symbols represent parameters. Subscripts in the parameters and functions refer to the state variable this parameter/function is associated with, while superscripts refer to the process. A complete list of the values and explanation of all parameters is given in Table 1. In choosing these parameters, we aimed at representing correctly the diatom-dominated, eutrophic coastal ecosystems and put less emphasis on the oligotrophic offshore environments. A description of the functions and the basis for our choice of parameters is presented in the online supplementary material, including a derivation of the source and sink term for the chlorophyll-to-carbon ratio, $J(\theta)$. We describe next solely the growth parameters for phytoplankton, as their role in regulating the phytoplankton distribution is discussed in detail in the results section. 
Phytoplankton growth is limited in our model by the amount of photosynthetically available radiation, $I$, and the concentrations of nitrate and ammonium. The effective growth is further constrained by temperature, $T$. Following Fasham et al. (1990), we assume that light and nutrient limitation are independent of each other, permitting us to write the total phytoplankton growth rate, $\mu_{P}$, as

$$
\mu_{P}\left(T, I, N_{n}, N_{r}\right)=\mu_{P}^{\max }(T, I) \cdot \gamma\left(N_{n}, N_{r}\right)
$$

where $\mu_{P}^{\max }(T, I)$ is the temperature-dependent, light-limited growth rate under nutrient replete conditions and $\gamma\left(N_{n}, N_{r}\right)$ is a non-dimensional nutrient limitation factor. The temperature-dependent, light-limited growth rate is given by

$$
\mu_{P}^{\max }(T, I)=\frac{\mu_{P}^{T}(T) \cdot \alpha_{P} \cdot I \cdot \theta}{\sqrt{\left(\mu_{P}^{T}(T)\right)^{2}+\left(\alpha_{P} \cdot I \cdot \theta\right)^{2}}}
$$

where $\alpha_{P}$ is the initial slope in the growth versus light relationship (see Table 1), and where $I$ stands for in situ PAR, given in $\mathrm{W} \mathrm{m}^{-2}$.

This light versus growth relationship is based on Smith (1936) and is identical to that used by Fasham et al. (1990), except that it has been modified to take into account variations in the chlorophyll-to-carbon ratio, $\theta$. This modification attempts to represent the expected increase in photosynthesis in response to phytoplankton cells allocating a higher percentage of their structure to the photosynthetic apparatus, i.e. having higher $\theta$. This should lead to higher growth rates in regions that are nearly nutrient-replete, such as within the upwelling zone, or in the proximity of the subsurface chlorophyll maximum. This modification is supported by the observation that $\alpha_{P}$ generally increases with decreasing cell volume, which in turn tends to be associated with faster 
growing phytoplankton populations (Geider et al., 1986). We did not adjust our light versus growth relationship for the fact that we are using a diurnally varying light field, while most previous studies used an integral form (Evans and Parslow, 1985). Sensitivity studies showed that the inclusion of a diurnally varying light field leads, on average, to lower growth with fixed $\mu_{P}^{T}(T)$ and $\alpha_{P}$, mainly because of the concave nature of the light versus growth relationship (10).

The temperature dependent growth rate, $\mu_{P}^{T}(T)$, is parameterized using the relationship of Eppley (1972),

$$
\mu_{P}^{T}(T)=\ln 2 \cdot 0.851 \cdot(1.066)^{T}
$$

where $T$ is given in degrees Celsius. A factor of $\ln 2$ was added to change the units in the relationship from the original doubling per day to day ${ }^{-1}$.

The nutrient limitation factor, $\gamma\left(N_{n}, N_{r}\right) \leq 1$, is parameterized using a MichaelisMenten equation, taking into account that ammonium is taken up preferentially over nitrate, and that its presence inhibits the uptake of nitrate by phytoplankton (Wroblewski, 1977). We use an additive function weighted toward ammonium:

$$
\gamma\left(N_{n}, N_{r}\right)=\gamma\left(N_{n}\right)+\gamma\left(N_{r}\right)=\frac{N_{n}}{K_{N_{n}}+N_{n}} \frac{K_{N_{r}}}{K_{N_{r}}+N_{r}}+\frac{N_{r}}{K_{N_{r}}+N_{r}}
$$

where $K_{N_{n}}$ and $K_{N_{r}}$ are the half-saturation constants for phytoplankton uptake of nitrate and ammonium, respectively. The ammonium inhibition term for nitrate uptake, $\left(K_{N_{r}}\right) /\left(K_{N_{r}}+N_{r}\right)$ is based on the work of Parker (1993), and has been shown to give nearly the same results as the exponential decay relationship originally used by Wroblewski (1977). 


\subsection{Optical Model}

We use a spectrally unresolved model to describe the penetration of photosyn-

thetically available radiation (PAR), $I$, into the water column. PAR is assumed to be attenuated by seawater with an attenuation coefficient, $\kappa_{s w}$, and by the presence of chlorophyll with a chlorophyll specific attenuation coefficient $\kappa_{\text {chla }}$ (see Table 1 for values). The subsurface profile of PAR, $I(z)$ is calculated by vertically integrating

$$
\frac{d I}{d z}=-\left(\kappa_{s w}+\kappa_{c h l a} \mathrm{Chl}-\mathrm{a}(z)\right) \cdot I(z)
$$

from the surface down to the bottom of the water column. The concentration of chlorophyll $a$, Chl-a, in units of $\mathrm{mg}$ Chl-a $\mathrm{m}^{-3}$ is computed from the phytoplankton concentration and the chlorophyll-to-carbon ratio, $\theta$, assuming a constant C:N ratio of 106:16.

Surface PAR is calculated from the total surface solar radiation used in the physical model, assuming that PAR represents $43 \%$ of total solar radiation at the sea surface. In order to resolve the diurnal cycle for PAR, we constructed a diurnally varying PAR field from the monthly climatology that drives the physical model. Details are given in the online supplementary material.

\subsection{Boundary and initial conditions, spinup, and convergence}

We force our physical model at the surface using monthly-mean climatologies of wind stress and fluxes of heat and freshwater derived from the Comprehensive Ocean Atmosphere Data Set (COADS) (da Silva et al., 1994). Our choice of neglecting synoptic and interannual variability in the surface boundary con- 
dition is based on our focus on the mean state of the CCS and its seasonal evolution. All non-seasonal variability in the model is therefore entirely intrinsic, i.e. generated by the instabilities in the flow. For further details on the lateral and surface boundary conditions, the reader is referred to the online supplementary material.

The model is initialized with climatological observations of temperature, salinity, and nitrate for the average of the months of December and January (Conkright et al., 2002) and no flow. The remaining state variables are set to very small, but non-zero values. Winter values are used because this is a period of minimum wind forcing and current energy, which reduces initial spinup problems.

From the above initial conditions, we run the $15+5 \mathrm{~km}$ configuration for 10 years forward in time. Time-series for the different state variables show that this configuration converges after about 3 to 4 years. Due to intense mesoand submesoscale variability, and the chaotic nature of these variations, we

find substantial year-to-year variations in our results even after the spinup. In order to remove these interannual variations, we generally show and discuss 5-year averages from year 6 through 10.

\section{Model Evaluation}

\subsection{Ocean Circulation}

Under the influences of climatological-mean seasonal forcing from the atmosphere and subtropical-gyre open boundary conditions, a robust equilibrium 
state is established for the CCS on a time scale of a few years. Marchesiello et al. (2003) demonstrated that this solution has mean alongshore, cross-shore, and boundary upwelling currents similar to those estimated from hydrographic climatologies. To evaluate our physical model results further, we compare here our results with the climatological distribution of SST measured by AVHRR (Figures 3) and the vertical structure of upper thermocline properties as observed by CalCOFI (Figure 5, data obtained from www.calcofi.org) and at station H3/M1 in Monterey Bay (Figure 6). We compare long-term averages in order to remove the effect of mesoscale eddies.

The annual average ROMS solution represents well the observed SST pattern in the CCS (Figure 3). In particular, the model successfully captures the offshore extent of the cold upwelling region along the central coast of California. However, absolute values of modeled SST exhibit a cold bias of about $1^{\circ} \mathrm{C}$ relative to AVHRR (Figure 3c) for most of the model domain. Modeled SST tend to be more consistent with the available CalCOFI data (Figure 4). Some of the differences between the two observational estimates are likely due to spatial and temporal representation error in the relatively sparsely sampled CalCOFI data, but we also need to consider that these differences reflect true changes over time. The CalCOFI climatology spans the period from 1949 to 2000, while the AVHRR climatology was put together on the basis of the years 1997 through 2002 only. As a result, the long-term warming that has been observed in the offshore region of the CCS (Roemmich and McGowan, 1995; Di Lorenzo et al., 2005) will lead to SST from AVHRR being warmer, on average, than those from CalCOFI. Given the observation of an approximately $1.6^{\circ} \mathrm{C}$ warming from the early 1950s to the late 1990s (Roemmich and McGowan, 1995; Di Lorenzo et al., 2005), the AVHRR climatology is expected to be about 
$1^{\circ} \mathrm{C}$ warmer than a climatology based on the entire record. Since our model was forced with heat fluxes from the COADS climatology, which was derived from observations collected between 1950 to 1979, we expect it to be more consistent with CalCOFI SST than with AVHRR based SST. We therefore regard at least part of our cold SST bias relative to AVHRR as representing a real difference. The cold bias in the nearshore regions is, on average, smaller (Figure 3c), indicating that the model is upwelling water with approximately the right temperature characteristics.

A comparison of the modeled versus observed vertical distribution of temperature along CalCOFI line 70 indicates that the simulated thermocline (Figure 5, panels (a) and (b)) is at about the right depth, but is underestimating the onshore slope, particularly in the nearshore region. Sensitivity experiments and theoretical considerations have shown that the large-scale onshore slope is to a significant degree determined by the magnitude and sign of the curl of the wind stress. In contrast, the slope of the isotherms in the very nearshore region is primarily determined by the alongshore wind stress along the coast (X. Capet, personal communication). In analogy to the open ocean, positive wind stress curl leads to a heaving of the isotherms. Comparison of the COADS winds with other wind products revealed that due to its coarse resolution COADS very likely underestimates the positive wind stress curl, explaining the underestimation of the offshore-onshore slope in the isotherms (X. Capet, personal communication). The modeled salinity distribution (Figure 5, panels (c) and (d)) is in good agreement with observations, except that it also exhibits too small a slope towards the coast. Since the contribution of salinity to density variations within the CCS is small (outside the Columbia River plume), salinity can almost be regarded as a passive tracer. Consequently, the 
underestimation of the onshore slope in salinity can be interpreted as simply reflecting the same issues with the wind stress and its curl as expressed in the temperature deficiency.

An additional evaluation of our physical model results is the comparison with the climatological mean annual cycle observed at the M1/H3 mooring site in Monterey Bay (Figure 6) (Pennington and Chavez, 2000). The model successfully reproduces the key characteristics of the seasonal evolution of the upper thermocline at this nearshore site, with a strong shoaling of the isotherms in spring/early summer and a deepening of them in late summer, fall and winter. However, the modeled thermocline is behaving too sluggishly relative to observations, with the amplitude of the shoaling of the isotherms being about $30 \%$ too small (e.g. for the $10^{\circ} \mathrm{C}$ isotherm, the shoaling amounts to about 70 $\mathrm{m}$ in the model, whereas the observations indicate a shoaling of more than 100 $\mathrm{m})$. We suspect that many of these differences arise because of the absence of synoptic variability in our physical forcing.

We conclude that, in agreement with the systematic evaluations of our U.S. West Coast physical solutions by Marchesiello et al. (2003), our model setup captures much of the spatial and temporal variability in ocean physics at the scale of the upwelling region (several hundred kilometers) and over a climatological annual cycle. As will be discussed below, this capability is key to obtaining realistic ecosystem solutions given the tight coupling between biogeochemical, ecological, and physical processes. 


\subsection{Biogeochemical and Ecosystem Properties}

The comparison of the modeled annual mean chlorophyll with that inferred by SeaWiFS (Figure 7) demonstrates the success and shortcoming of our solutions even more clearly than SST. South of the region around Cape Mendocino, i.e. south of about $40.5^{\circ} \mathrm{N}$, the model successfully reproduces both the average chlorophyll concentration in the nearshore $50 \mathrm{~km}$, as well as the negative gradient along an onshore-offshore transect. Similar conclusions are found by comparing modeled near surface chlorophyll with those measured in situ by the CalCOFI program in this region (Figure 4b). However, a detailed inspection also reveals that the model simulates much higher chlorophyll in the very nearshore region, i.e. within the first $25 \mathrm{~km}$, compared to both CalCOFI and SeaWiFS. In the case of SeaWiFS, one would need to be careful with a quantitative comparison, since the retrieval algorithm has not been optimized for quantitatively determining chlorophyll in coastal waters (Toole and Siegel, 2001).

In contrast to the relative success in the southern part of our domain, chlorophyll begins to be underestimated by our model north of Cape Mendocino, i.e. $40.5^{\circ} \mathrm{N}$, and remains much lower than observations north of Cape Blanco $\left(43^{\circ} \mathrm{N}\right)$ all along the Oregon coast. The largest absolute underestimation is found in the nearshore region, where annual mean chlorophyll simulated by the model is well below $1 \mathrm{mg}$ Chl-a $\mathrm{m}^{-3}$, whereas observed annual mean chlorophyll is above this value along the entire coast, reaching values as high as 6 mg Chl-a $\mathrm{m}^{-3}$ in a few locations. This negative bias extends far into the offshore regions, where modeled chlorophyll fields are persistently lower than the observed ones by about a factor of three. We suspect that a substantial 
part of this bias is a result of our use of COADS wind products that lack the synoptic variability that is typical for the Oregon/Washington coasts. Coastal upwelling in these regions is much more intermittent, driven by short bursts of strong upwelling, and interleaved by relaxation periods (Huyer, 1983). Simulations by Spitz et al. (2005) clearly demonstrate the importance of these upwelling events, which are not well represented in our forcing. A monthly mean wind product will therefore underestimate the upwelling. Furthermore, small-scale wind patterns around complex topography (Dong and McWilliams, 2006), which are not represented in the COADS climatology, may further lead to biases. Future sensitivity studies with differing wind products (c.f. Capet et al. (2004)) will hopefully resolve this bias.

Figure 8 shows that the good agreement between modeled and observed chlorophyll for the southern portion of our domain extends to all seasons. The largest difference is found in fall, when the offshore extent of the high chlorophyll region is too small. The seasonal comparison also reveals that most of the large bias in the northern portion of our domain, i.e. north of Cape Mendocino, is driven by a virtual absence of elevated chlorophyll in fall and winter, the seasons of greater storminess. The negative bias does not disappear in spring and summer, but is notably smaller.

A more quantitative comparison between the modeled and observed chlorophyll distributions is depicted in the Taylor diagrams shown in Figure 9 (Taylor, 2001). A Taylor diagram combines information about the correlation between the modeled and observed pattern (plotted as the angle between the abscissa and the line drawn from the origin to the point) with the standard deviation of the modeled field relative to that of the observed field (distance from origin to the point along the angle given by the correlation). On this 
plot, the observed pattern lies on the abscissa at distance 1 from the origin, since it correlates perfectly with itself and has a normalized standard deviation of 1 . The centered pattern root mean square (RMS) error is then given by the distance between the point defined by the modeled pattern and the observed pattern. The shorter this distance, the greater the agreement between the pattern.

Figure 9a shows for the annual mean chlorophyll pattern over the entire domain (point denoted by "DOMAIN") a correlation of about 0.6 between the model simulated field and the observations inferred from SeaWiFS. The model underestimates the observed variance somewhat by having a standard deviation around the annual mean of the entire domain that is about $20 \%$ smaller than the observed standard deviation. The large difference in the success of our model in simulating the pattern north and south of Cape Mendocino becomes evident by computing the correlations and standard deviations separately for these two regions. The southern part of our domain has a correlation exceeding 0.8 with a standard deviation that is nearly identical to the observed one, whereas the northern part has a correlation of only about 0.3 , with a standard deviation that is only half of the observed one. As a result, the RMS between the model and the observations is more than $50 \%$ larger in the northern compared to the southern part of the domain. The north-south difference is somewhat less pronounced in the nearshore region "Nearshore" (defined as a $100 \mathrm{~km}$ wide strip following the coastline).

The model simulates the observed seasonal cycle of chlorophyll less successfully than the annual mean pattern (Figure 9b). The correlation of the seasonal anomalies, i.e. of the monthly means minus the annual means, for the entire domain is only 0.4 , and none of the subregions has a correlation above 0.6. 
The best agreement is found for the nearshore region in the northern part of our domain, but its RMS is only marginally better than the worst RMS found for any of the sub-regions in the annual mean case. This distinct difference between the annual mean and the seasonal component is not reflected in the Taylor diagrams for SST (Figure 9c-d), which show generally much better agreement and no major distinction between the two temporal components. The correlation for both annual mean SST and its seasonal component amounts to nearly 0.99 and the model variance is very close to the observed one. This is a remarkable success, but it needs to be added that by plotting correlations and standard deviations only, the model bias for SST identified above (Figure 3c) is not considered here.

In order to evaluate our subsurface modeled fields, we turn to the observations from the CalCOFI program and the M1/H3 mooring in Monterey Bay. The comparison of simulated and measured depth distributions of nitrate and chlorophyll along CalCOFI line 70 presents a supporting picture, although several mismatches can be identified (Figure 5). The mean nutricline in the model is very close to the observed one, but reminiscent of the comparison with temperature and salinity, the modeled isolines fail to show the shoreward shoaling seen in the observations, particularly in the nearshore region.

The vertical distribution of the modeled chlorophyll compares relatively well with the available CalCOFI data. The model successfully captures the nearsurface chlorophyll maximum in the nearshore zone, followed by a progressive deepening of the chlorophyll maximum as the transect moves offshore, for reasons discussed in section 4.1 below. The model tends to overestimate the chlorophyll concentration of this deep chlorophyll maximum and also tends to exhibit too deep a penetration of sizeable chlorophyll concentrations. This 
overestimation could be driven by a too large Chl-a:C ratio, or by an overestimation of the phytoplankton biomass. We unfortunately lack in situ observations of either of these two quantities, so we cannot distinguish between these two possibilities, but the simulation of a too deep nitracline (Figure 5) suggests that the latter cause may be the main source of the discrepancy. We suspect that our chosen value for the initial slope of the phytoplankton response to light, i.e. $\alpha_{P}$, may be too large.

Figure 6 shows that the model successfully captures the upward lifting of the nutricline at the Monterey Bay site during the summer upwelling season, leading to the injection of new nutrients into the near surface ocean. The model also simulates the relaxation during winter, when near surface nitrate drops to very low values and the entire upper $50 \mathrm{~m}$ become nitrate deficient. As was the case for temperature, the observed magnitude of this seasonal contrast is not fully reproduced by the model. It underestimates both the upward lifting of the high nitrate waters in summer and the downward relaxation of the low nitrate waters in winter. In addition, the thermocline nitrate concentration for a given temperature tends to be lower in the model in comparison to the observations, potentially aggravating the nutrient injection bias by the too small upward lifting of the thermocline in the summer season. Despite these shortcomings, model simulated chlorophyll values in Monterey Bay compare remarkably well with observations, with the main difference being a later onset of the seasonal chlorophyll maximum in summer. The observations indicate a maximum in spring and early summer, whereas the seasonal maximum in the model occurs in late summer.

In summary, the evaluation of our simulated fields with in situ and remotely sensed biological and biogeochemical properties suggest that the model cap- 
tures the large-scale pattern and their seasonal evolution remarkably well. Some mismatches can be traced back to deficiencies in the physical model, e.g. induced by the lack of synoptic wind forcing and potential biases in the spatial resolution of the winds, while other deficiencies are clearly related to the ecological/biogeochemical model. The largest structural problem is, perhaps, our use of a single phytoplankton functional group model, which prevents the ecological model from switching between eutrophic and oligotrophic conditions. Since our focus here is on the eutrophic upwelling system, we accept this shortcoming.

\section{Upper Ocean Ecosystem Structure and Dynamics}

We next discuss the different biomass pools in the upper ocean with an emphasis on the processes that control their spatio-temporal pattern. We focus on the central California upwelling system, where our model evaluations provided us with confidence that the model is able to capture the most important processes governing upper ocean ecosystem dynamics.

We limit our discussion to the distribution of the various ecosystem variables within the euphotic zone (defined here as the $1 \%$ light level), whose depth varies between about $50 \mathrm{~m}$ in the nearshore and more than $100 \mathrm{~m}$ in the offshore waters. This distribution is entirely governed by chlorophyll, since this is the only property that absorbs light besides water in our model. These euphotic zone depths are everywhere deeper than the model's mixed layer depths, which are between 40 to $50 \mathrm{~m}$ deep in winter, and shoal to $20 \mathrm{~m}$ and less in summer. These mixed layer depths are also substantially shallower than the critical depth (Sverdrup, 1953), which is of the order of $100 \mathrm{~m}$ and more (Platt 
et al., 1991; Siegel et al., 2002). The critical depth is defined as the depth at which the vertically integrated rates of photosynthesis and community respiration are equal. This suggests that although our model phytoplankton within the surface mixed layer will experience light limitation, it has always enough light to sustain positive net growth.

\subsection{Phytoplankton}

The annual mean distribution of phytoplankton biomass averaged over the euphotic zone (Figure 10a) shows a slower transition than surface ocean chlorophyll from the high levels nearshore to the lower values offshore. This slower transition is primarily due to phytoplankton biomass transitioning from a surface maximum in the nutrient rich nearshore region to a deep phytoplankton biomass maximum in the offshore region (see Figure 11c). The variable Chl-a:C ratio considered in our model has little influence on this result, since surface phytoplankton has a relatively constant ratio in our model (see below).

The phytoplankton biomass transition from a nearshore surface to an offshore subsurface maximum is mainly a result of the interaction of light and nutrient availability. Ample light and nutrients in the surface waters of the nearshore regions permit phytoplankton to grow near maximum growth rates there. As evidenced in Figure 12, however, surface nitrate concentrations get rapidly drawn down as the upwelled waters are transported offshore by the mean Ekman drift and the abundant meso- and submesoscale circulation features. While phytoplankton uptake draws surface nitrate down to levels below 0.05 mmol $\mathrm{m}^{-3}$ (more than 15 times lower than the half-saturation concentration for nitrate uptake) in the offshore waters, surface ammonium concentrations 
remain somewhat elevated between 0.05 and $0.10 \mathrm{mmol} \mathrm{m}^{-3}$. This is caused by an active ammonium cycle consisting of rapid phytoplankton uptake, and generation by zooplankton excretion and the breakdown of (small) detritus. However, this ammonium concentration is too low to sustain high phytoplankton growth rates in the near surface waters, since it is 5 to 10 times smaller than our half-saturation concentration for ammonium uptake. In contrast, elevated nitrate and ammonium concentrations at depth in the offshore regions permit phytoplankton to sustain an appreciable amount of biomass despite the reduced light level (the deep phytoplankton biomass maximum is located only slightly above the $1 \%$ light level). Although this essentially local growth argument explains most of the depth transition of the phytoplankton biomass, some of the phytoplankton is transported there by downwelling and subduction processes as well.

The interaction of light and nutrients and their influence on local growth, as well as the influence of lateral transport are particularly evident when the seasonal evolution of phytoplankton biomass along the same offshore section is investigated (see Figure 13). In winter, phytoplankton biomass is comparatively low and vertically nearly homogeneously distributed. This is driven primarily by the presence of deeper mixed layers, particularly offshore, which mix the phytoplankton biomass vertically. In the offshore region, this dilution effect is not compensated by increased growth from the mixing-induced enhanced nutrient input, because of the lower light levels available at this time of the year. This light limiting effect is particularly strong in the lower parts of the euphotic zone. The light levels are, however, not low enough to remove the light inhibition of nitrification, so that substantial levels of ammonium are built up at the base of the euphotic zone (Figure 11b). 
As the upwelling season starts in spring, near surface phytoplankton biomass in the nearshore region rapidly increases, forming a distinct near surface maximum. Some of this elevated phytoplankton biomass is transported offshore and downward forming distinct blobs of elevated phytoplankton biomass at depth. Small detrital material is transported alongside phytoplankton as well, forming a source of ammonium that can then fuel additional local growth. In summer, the nearshore and offshore systems appear to become uncoupled, with the nearshore region having continued high growth supporting high phytoplankton biomass in near surface waters, while a strong phytoplankton biomass maximum develops near the base of the euphotic zone in the offshore region. The offshore subsurface biomass maximum is maintained through summer and into early fall by lateral advection and local growth, fueled by high nutrients and a relaxation of the local light limitation as the surface chlorophyll concentrations drop. In fall, when coastal upwelling in the central California region starts to decrease, nearshore phytoplankton levels drop sharply, but the maximum remains near the surface. In the meantime, the offshore region continues to show elevated phytoplankton biomass at depth, which erode only slowly into winter.

The relative roles of light and nutrients in controlling the growth rate of phytoplankton can be diagnosed in more detail by splitting the phytoplankton growth rate, $\mu_{P}\left(T, I, N_{n}, N_{r}\right)$, into its individual driving factors. We obtain this separation by extending the growth rate equation (9) by the light-saturated growth rate $\mu_{P}^{T}(T)$, i.e.

$$
\begin{aligned}
\mu_{P}\left(T, I, N_{n}, N_{r}\right) & =\left(\frac{\mu_{P}^{\max }(T, I)}{\mu_{P}^{T}(T)} \cdot \gamma\left(N_{n}, N_{r}\right)\right) \cdot \mu_{P}^{T}(T) \\
& =\gamma(I) \cdot \gamma\left(N_{n}, N_{r}\right) \cdot \mu_{P}^{T}(T)
\end{aligned}
$$


where $\gamma(I)$ is the ratio of the light-limited growth rate $\mu_{P}^{\max }(T, I)$ to the lightunlimited growth rate $\mu_{P}^{T}(T)$. If either of these two factors, $\gamma(I)$ or $\gamma\left(N_{n}, N_{r}\right)$ is equal to 1 , then phytoplankton growth is completely unlimited by this factor. If either of these factors is equal to 0 , then phytoplankton growth is zero. In between, whichever factor is smaller has a stronger limiting influence on growth. Since both $\gamma(I)$ and $\gamma\left(N_{n}, N_{r}\right)$ have very similar concave shapes, i.e. negative second derivatives, a smaller value implies a larger sensitivity in $\gamma$ to a fractional change in either light or nutrients. Therefore, this condition satisfies the Monod-type condition for a proximate limiting factor (see Monod (1949))

Figure 14 shows annual mean vertical sections of $\gamma(I), \gamma\left(N_{n}, N_{r}\right)$, and the logarithm of their ratio, $\log \left(\gamma\left(N_{n}, N_{r}\right) / \gamma(I)\right)$, along the same offshore transect as shown before for phytoplankton (Figure 11c). The light and nutrient limitation terms show the expected nearly orthogonal pattern. The light limiting term is maximal in near surface waters and then decreases rapidly with depth, while the nutrient limiting term is maximal at depth and decreases toward the surface, except in the nearshore region. The latter pattern reflects directly the combined concentrations of nitrate and ammonium shown in Figure 11a and b. In contrast, by exhibiting a substantial offshore decrease from a maximum in the nearshore region, the light limiting term shows more variations than expected based on the distribution of PAR. The substantially lower values of $\gamma(I)$ in the offshore region are driven by low values of the Chl-a:C ratio, which reduces the efficiency by which phytoplankton is capable of absorbing the incoming PAR, reducing its growth rate.

The section of the logarithm of the ratio, $\log \left(\gamma\left(N_{n}, N_{r}\right) / \gamma(I)\right)$, (Figure 14c) demonstrates that, except for a relatively thin layer of about $20 \mathrm{~m}$ depth near 
the surface, phytoplankton growth in the annual mean is primarily limited by light. For most of the euphotic zone, light limitation exceeds nutrient limitation by a factor of 2 . In the nearshore region, this light limitation extends to the surface, while in the offshore region, nutrients are the proximate factor limiting phytoplankton growth. Part of the reason for the surprisingly large importance of light in controlling phytoplankton growth are the high concentrations of ammonium simulated in the euphotic zone of our model, which leads to a substantial increase in the nutrient limiting factor, $\gamma\left(N_{n}, N_{r}\right)$. We suspect that without the intense ammonium recycling exhibited by our model, the dominance of nutrient limitation would extend much deeper into the thermocline, particularly in the offshore region. A second caveat to consider is our neglect of a possible iron limitation, such as reported by Hutchins et al. (1998) and Hutchins and Bruland (1998) for the CCS. If iron is indeed an important factor limiting growth in the CCS, nutrient limitation may be more dominant than simulated by our model.

\subsection{Chlorophyll-to-Carbon Ratio}

In many coupled physical-ecosystem models, the chlorophyll-to-carbon ratio is assumed to be constant, with typical values of around $20 \mu \mathrm{g}$ Chl-a $(\mathrm{mg} \mathrm{C})^{-1}$ (this corresponds to a carbon-to-chlorophyll ratio of $50 \mathrm{mg} \mathrm{C}(\mathrm{mg} \mathrm{Chl}-\mathrm{a})^{-1}$ ) (e.g. Sarmiento et al. (1993); Fasham et al. (1993)). We therefore discuss next how our model simulated chlorophyll-to-carbon ratio varies and how much of a difference it makes in comparison to assuming it to be constant.

Figure 15 reveals that the primary factor determining the variations of $\theta$ in our model is the availability of light, as there is a strong increase in $\theta$ from near 
surface values of around 10 to $30 \mu \mathrm{g}$ Chl-a $(\mathrm{mg} \mathrm{C})^{-1}$ to values approaching $\theta^{\max }$ of $53 \mu \mathrm{g}$ Chl-a $(\mathrm{mg} \mathrm{C})^{-1}$ at the bottom of the euphotic zone. Another factor appears to be nutrient availability as nearshore surface waters tend to have higher $\theta$ values than offshore waters.

These variations can be well understood by analyzing equation (9) in the online supplementary material, which was derived from the model of Geider et al. (1997) and forms the basis for our model of $\theta$. This equation describes the fraction of freshly photosynthetically fixed carbon, $\alpha$, that is used for chlorophyll biosynthesis. Thus, when $\alpha$ is high, the chlorophyll-to-carbon ratio will increase, and vice versa. After inserting our parameterization for $\mu_{P}^{\max }(T, I)$ from (10), we obtain,

$$
\alpha=\frac{\mu_{P}^{T}(T) \cdot \gamma\left(N_{n}, N_{r}\right) \cdot \theta^{\max } \cdot \beta}{\sqrt{\left(\mu_{P}^{T}(T)\right)^{2}+\left(\alpha_{P} \cdot I \cdot \theta\right)^{2}}}
$$

where we use the symbol $\beta$ for denoting the product of the conversion factors $r_{C: N}^{P}$ and $12 \mathrm{mg} \mathrm{C}(\mathrm{mmol} \mathrm{C})^{-1}$.

In the case of high irradiance, typical for near surface waters, the second term within the square root is much larger than the first term, so that (16) converges to a solution that is inversely proportional to the amount of irradiance and proportional to the nutrient concentration, expressed by the factor $\gamma\left(N_{n}, N_{r}\right)$ :

$$
\alpha^{\text {high light }}=\frac{\mu_{P}^{T}(T) \cdot \gamma\left(N_{n}, N_{r}\right) \cdot \theta^{\max } \cdot \beta}{\alpha_{P} \cdot I \cdot \theta}
$$

This explains the generally low $\theta$ values in near surface waters, and also the increase toward the more productive nearshore region. While we lack observations to assess our modeled distribution of $\theta$, there exist time-series observations from near surface waters in the highly productive Monterey Bay (F. Chavez, pers. comm). Comparison of our modeled surface Chl-a:C ratios for 
Monterey Bay surface waters show an excellent agreement with these observations. Both model and observations have a winter maximum of $\theta$ with values around $35 \mu \mathrm{g}$ Chl-a $(\mathrm{mg} \mathrm{C})^{-1}$, decreasing to a summer minimum of around $25 \mu \mathrm{g}$ Chl-a $(\mathrm{mg} \mathrm{C})^{-1}$.

In the case of low irradiance, as encountered at the bottom of the euphotic zone, the first term within the square root is much larger than the second term, so that (16) converges to a solution that is determined by the nutrient status and $\theta^{\max }$ :

$$
\alpha^{\text {low light }}=\gamma\left(N_{n}, N_{r}\right) \cdot \theta^{\max } \cdot \beta
$$

Since nutrients often tend to be well above their half-saturation constants at depth, the factor $\gamma\left(N_{n}, N_{r}\right)$ is near 1 there (see Figure 14b), explaining why $\theta$ converges to $\theta^{\max }$ at the bottom of the euphotic zone.

The large horizontal and vertical variations in $\theta$ tend to cancel out in the vertical average over the euphotic zone (Figure 15c), so that the euphotic mean $\theta$ varies only between about 20 and $30 \mu \mathrm{g}$ Chl-a $(\mathrm{mg} \mathrm{C})^{-1}$. Most of the euphotic mean variations can be traced to either higher growth rates (nearshore) or lower average light levels (higher latitudes). This means that the non-linearities in (16) are relatively small, so that its vertical integral is primarily determined by the amount of light arriving at the sea surface.

Given the relatively small variations of the euphotic mean $\theta$, does our consideration of a variable chlorophyll-to-carbon ratio matter (see also discussion by Doney et al. (1996) and Armstrong (2006))? The benefit is relatively small when the simulation of euphotic mean phytoplankton biomass and the associated chlorophyll is considered, but has a substantial influence on their ver- 
tical distributions. A particularly large impact of using a variable ratio exists for the interpretation of satellite chlorophyll. Had we used a canonical value of $25 \mu \mathrm{g}$ Chl-a $(\mathrm{mg} \mathrm{C})^{-1}$ for converting our model simulated phytoplankton biomass into chlorophyll, we would have obtained higher chlorophyll nearly everywhere, except for the very nearshore region, where we would have obtained lower chlorophyll. This would have given us rather different skill scores in the Taylor diagram (Figure 9). The variable chlorophyll-to-carbon ratio is also of great importance when model simulated chlorophyll is compared to in situ observations, particularly at depth. In this case, using a canonical $\theta$ of 25

$\mu \mathrm{g}$ Chl-a (mg C) ${ }^{-1}$ would lead to much lower chlorophyll values, from which one would conclude a very substantial negative bias in the model.

\subsection{Zooplankton}

The annual mean zooplankton distribution in the euphotic zone exhibits an offshore gradient that is more pronounced than that of phytoplankton (compare panels a and b in Figure 10). Furthermore, zooplankton in the nearshore region tends to be more abundant in the southern part of the domain, while phytoplankton biomass is meridionally more evenly distributed. In the offshore regions, zooplankton disappears in regions where phytoplankton still maintains a substantial biomass. The reason for this result is that although phytoplankton biomass is well above zero, it is below the minimum level required to sustain zooplankton in our model. In steady-state, this minimum phytoplankton level, $P^{\text {min }}$ can be computed from the zooplankton conservation equation by setting $J(Z)$ in (3) to zero, solving the resulting equation for 
$Z$, and then setting that equation to zero. The resulting equation

$$
P^{\text {min }}=\frac{K_{P}}{g_{Z}^{g r a z} \cdot \beta_{Z}^{a s s i m} / \eta_{Z}^{\text {metab }}-1},
$$

shows that with the parameter values from Table 1, the minimum phytoplankton biomass to sustain zooplankton, $P^{\mathrm{min}}$, is $0.29 \mathrm{mmol} \mathrm{N} \mathrm{m}^{-3}$. Comparison of this steady-state minimum value with the distribution of phytoplankton biomass in Figure 10a shows that offshore phytoplankton biomass is indeed too low to sustain a zooplankton population.

This is fundamentally inconsistent with observations. The phytoplankton threshold for zooplankton growth is an artifact of our model structure and parameter choices. In reality, the offshore transition from large to small phytoplankton has a corresponding transition of the dominant grazers from mesozooplankton to microzooplankton. Since we chose our zooplankton parameters to mimic mesozooplankton, our model is structurally inept to mimic this transition. As a result, zooplankton disappears from the offshore system, making coagulation and phytoplankton mortality rather than grazing the dominant loss terms for phytoplankton there, which is opposite to what is known about phytoplankton loss in oligotrophic systems (e.g. Roman et al. (2002)).

In the vertical, zooplankton in our model nearly always shows a maximum near the surface, as evidenced in its annual mean distribution (Figure 11d). This surface maximum is a result of the nearshore region being the only region that can sustain a zooplankton population. Offshore values of phytoplankton biomass, even at the depth of the phytoplankton biomass maximum, are nearly always below the above threshold of $0.29 \mathrm{mmol} \mathrm{N} \mathrm{m}^{-3}$, except for brief periods in summer, so that zooplankton has great difficulties growing there. 
The abundance and distribution of the simulated zooplankton population is highly sensitive to our choice of the zooplankton parameters, which are not well constrained by the literature. Unfortunately, there exist very few zooplankton biomass observations, to which we can quantitatively compare our model results. This is because most zooplankton observations are reported as zooplankton biomass displacement volumes. Roemmich and McGowan (1995) report for the upper ocean and for the stations inshore of $100 \mathrm{~km}$ along CalCOFI line 80 (extending southwestward from Point Conception) mean values of about $250 \mathrm{ml}$ zooplankton volume per $1000 \mathrm{~m}^{3}$ seawater strained for the period 1951 to 1957 , decreasing to about $60 \mathrm{ml}\left(1000 \mathrm{~m}^{3}\right)^{-1}$ for the period 1987 to 1993 . Using the recommended conversion factor of $96 \mathrm{mg} \mathrm{C}(\mathrm{ml}$ zooplankton $)^{-1}$ of Cushing et al. (1958) and assuming a fixed C:N ratio of 6.6, these volumes correspond to a zooplankton biomass ranging from $0.07 \mathrm{mmol}$ $\mathrm{N} \mathrm{m}^{-3}$ (1987-1993) to $0.3 \mathrm{mmol} \mathrm{N} \mathrm{m}^{-3}$ (1951-1957). The long-term climatology of zooplankton biomass for the nearshore CCS (O'Brien et al., 2002) suggests somewhat higher values with biomass levels between 0.1 and $1 \mathrm{mmol}$ $\mathrm{N} \mathrm{m}^{-3}$, in agreement with detailed observations made in Monterey Bay (B. Marinovic, pers. comm.). Our simulated euphotic mean zooplankton biomass levels of between 0.1 and $0.6 \mathrm{mmol} \mathrm{N} \mathrm{m}^{-3}$ (Figure 10b) compare therefore well in magnitude to these in situ observations. More detailed comparisons with a more careful consideration of the displacement volume to biomass conversion factor are needed, however, to evaluate our zooplankton simulations more quantitatively. 


\subsection{Detrital pools}

The two modeled detrital pools exhibit strikingly different annual mean distributions within the euphotic zone (Figure 10). Small detritus has a distribution very similar to phytoplankton biomass both in terms of pattern and magnitude, while large detritus is essentially concentrated very nearshore, with concentrations that are an order of magnitude smaller than that of small detritus. Most of the onshore-offshore contrast is due to their different sinking characteristics. Given our choices for sinking speeds for the two detrital pools and their remineralization rates (see Table 1), the remineralization length scales for the two pools vary dramatically between $30 \mathrm{~m}$ for small detritus and 1000 $\mathrm{m}$ for large detritus. As a result, small detritus barely sinks, making it susceptible to offshore transport, while large detritus, once formed, disappears very rapidly from the euphotic zone. This difference is illustrated in the ver-

tical sections (cf. Figure 11, compare panels e and f), which show a tongue of high concentrations of large detritus extending from the euphotic zone into the ocean interior, while the small detritus has no appreciable concentrations below $200 \mathrm{~m}$.

A second, albeit less important factor causing the large onshore-offshore difference in the distribution of small and large detritus are their differing formation mechanisms. In the nearshore region, phytoplankton and small detritus concentrations are high, making coagulation an important sink for these two components. This is because of the square dependence of coagulation on the phytoplankton and small detritus concentrations. In addition, zooplankton is abundant, further increasing the production of large detritus by its mortality as well as by sloppy feeding and the production of fecal pellets. In contrast, 
phytoplankton, small detritus, and zooplankton concentrations are small in the offshore region, making coagulation less efficient and all the zooplankton formation mechanisms for large detritus virtually absent.

The similarity in pattern and magnitude of small detrital material to phytoplankton will be discussed in detail in the next section. In summary, the similarity in the offshore region can be explained by considering the steady-state condition of formation equalling loss. In the nearshore region, steady-state conditions would require much higher small detrital material concentrations, but those are not attained because the residence time of waters in these regions is too short for small detritus to come to equilibrium.

Given that the parameters governing phytoplankton mortality, particle remineralization, and coagulation are not well constrained in the literature, our parameter choices need to be viewed as somewhat arbitrary. We can evaluate the combined impact of these parameters by comparing the simulated detrital fields with observations. Unfortunately, we are not aware of any systematic assessment of particulate organic matter (POM) in the CCS, except for a few observations that indicate that living biomass is about half of total POM (Eppley et al., 1983; Eppley, 1986). Gardner et al. (2006) recently estimated the distribution of POM in the ocean using a combination of in situ measurements and satellite observations. They showed that in the CCS, about $1 \%$ of POC in $\mathrm{mg} \mathrm{m}^{-3}$ exists in the form of Chl-a in $\mathrm{mg}$ Chl-a $\mathrm{m}^{-3}$. Dividing this number with our average surface ocean chlorophyll-to-carbon ratio, $\theta$, of about $20 \mu \mathrm{g}$ Chl-a $(\mathrm{mg} \mathrm{C})^{-1}$, we estimate a phytoplankton biomass to total organic matter ratio of about 0.5 , in excellent agreement with our results. This agreement needs to be viewed cautiously, however, as Gardner et al. (2006) developed their algorithm for the estimation of POM for open ocean environments, and 
therefore this algorithm may not work well in the more turbid coastal waters.

\section{$5 \quad$ Nitrogen allocation}

A powerful tool to understand ecosystem structure is the analysis of how nitrogen is allocated to the different nitrogen pools as a function of the total amount of fixed nitrogen in the system (see e.g. DeAngelis (1992) and Sarmiento and Gruber (2006)). It is instructive, however, to first investigate the relative allocation in the spatial context.

Figure 16 shows the annual mean concentrations of the 6 fixed nitrogen bearing ecosystem state variables in the near surface ocean as a function of longitude (offshore distance) for a section across the central California upwelling system. The total amount of surface nitrogen in the system decreases from a maximum at the coast relatively monotonically with increasing offshore distance, reflecting the supply of new nitrogen into the surface ocean by upwelling nearshore and the subsequent loss of nitrogen by sinking organic nitrogen as the water ages along its mean offshore transport pathway. This overall trend is the sum of similar trends exhibited by the individual nitrogen pools except for the very nearshore region, where phytoplankton, zooplankton, and detritus are lower than further offshore. This is a result of upwelling waters containing low concentrations of these state variables, requiring some time and some aging of the upwelled waters for these pools to grow in. In the first $100 \mathrm{~km}$, the total nitrogen content of the system is dominated by nitrate, while further offshore, phytoplankton and small detritus become the dominant nitrogen pools.

When plotted as a function of the total nitrogen content, these two distinct 
regimes emerge more clearly (Figure 17). Above a total nitrogen content of about $3 \mathrm{mmol} \mathrm{N} \mathrm{m}^{-3}$, nitrate dominates, and most other nitrogen pools decrease in relationship to phytoplankton. Below this threshold, phytoplankton and small detritus are the dominant pools of nitrogen in the system, and most pools increase their size relative to phytoplankton as more nitrogen becomes available. Is this behavior an intrinsic property of the ecosystem model, or is this difference between low and high total nitrogen content driven by the physical dynamics of the upwelling system? We address this question by contrasting our ecosystem model results in the 3-D configuration with those obtained in a box model configuration that does not consider lateral transport. The latter configuration is thus stripped of all the complexities involved in the 3-D nature of transport and mixing and therefore permits us to clearly delineate the ecosystem model intrinsic part of our solutions. Furthermore, the box model configuration is amenable to analytical steady-state solutions so that we can also determine whether differences between the two physical configurations are caused by the absence of local steady-states, i.e. balances between biological sources and sinks.

We therefore implemented our ecological/biogeochemical model into a box model configuration, which consists of a well mixed surface box of $h=20 \mathrm{~m}$ depth, and an underlying thermocline box, for which all concentrations are prescribed to be zero, except for nitrate, which is set to $N_{n}^{t h}=20 \mathrm{mmol} \mathrm{N}$ $\mathrm{m}^{-3}$. The level of nitrate input into the surface box is determined by $-w / h$. $\left(N_{n}^{t h}-N_{n}\right)$, where $w$ is the vertical upwelling velocity. This exchange only affects nitrate, i.e. we do not consider the potential for the washing out of phytoplankton, etc., as would occur in a chemostat with inflow and outflow. In order to achieve solutions with a widely differing amount of total nitrogen 
in the surface box, we varied $w$ in our box model simulations from $0.001 \mathrm{~m}$ day $^{-1}$ to $15 \mathrm{~m} \mathrm{day}^{-1}$. As is the case with the $3-\mathrm{D}$ model, phytoplankton and the two detrital pools are subject to sinking. All ecosystem parameters are the same as in 3-D. We created light saturated conditions by adopting a PAR of $500 \mathrm{~W} \mathrm{~m}^{-2}$ in order to focus on the role of nutrients. This box model is then run forward in time for different levels of nitrate input into the surface box until a steady-state is reached.

A comparison of the box model results with those obtained in the 3-D model reveals that phytoplankton and zooplankton behave similarly in both configurations when plotted as a function of the total nitrogen content, while the detrital pools, nitrate, and ammonium show strongly differing relationships (Figure 18). The largest difference is exhibited by nitrate, which is drawn down to very low levels in the box model regardless of how much nitrogen is in the system. Is this difference due to the different physical setting or is this an expression of the ecosystem being far from steady-state in the 3-D configuration? We address this question for each state variable in turn.

\subsection{Phytoplankton}

The close correspondence between the 3-D and the box model results could lead to the conclusion that phytoplankton has achieved a local steady-state in the 3-D configuration, i.e. that its growth and biological losses are locally balanced. This appears reasonable given the fact that at the light and nutrient saturated conditions typical for the nearshore region, growth rates are of the order of 1 to 2 day $^{-1}$ (see Figure 14). This gives an e-folding response time of 0.5 to 1 day, likely fast enough to respond to the frequent physical 
perturbations imposed by the abundant meso- and submesoscale phenomena.

A closer inspection reveals a more complex story, however. Given the fact that the nutrients nitrate and ammonium hover around $0.1 \mathrm{mmol} \mathrm{m}^{-3}$ in the box model solutions, but attain very high concentrations in the $3-\mathrm{D}$ simulations, the phytoplankton growth rates associated with a particular level of phytoplankton biomass are much larger in the 3-D compared to the box model configuration. This creates a puzzle since steady-state requires that the higher growth rates in $3-\mathrm{D}$ are compensated by higher loss rates, yet the loss by mortality and by zooplankton grazing is about the same in both configurations, because both have about the same zooplankton biomass for a given phytoplankton biomass (Figure 18a). This requires that additional loss mechanisms remove phytoplankton biomass in 3-D, which do not exist in the box model. The only mechanism of note is the lateral transport of phytoplankton. Therefore, at the same phytoplankton biomass level, the balance in the box model is between growth and grazing, both occurring at relatively low rates, whereas the balance in 3-D is between growth and lateral loss, both occurring at high rates. The similar scaling between the $3-\mathrm{D}$ and box model configurations when phytoplankton biomass is plotted as a function of total nitrogen content is therefore coincidental.

\subsection{Zooplankton}

The relatively small differences in the zooplankton allocation between the 3-D and box model results (Figure 18) is depicted in more detail in Figure 19a, which shows abundances normalized to and as a function of phytoplankton nitrogen. The 3 -D results for the zooplankton to phytoplankton ratio $(Z / P)$ 
are within a factor of two of the box model solutions (Figure 19). This indicates that, to first order, zooplankton biomass is controlled by the same balance in both configurations. In the absence of advective loss terms, the analytical steady-state of $Z / P$ is given by

$$
(Z / P)^{\text {steady-state }}=\frac{g_{Z}^{\text {graz }} \beta_{Z}^{\text {assim }}-\eta_{Z}^{\text {metab }}\left(\frac{K_{P}}{P}+1\right)}{\eta_{Z}^{\text {mort }}\left(K_{P}+P\right)} .
$$

i.e. this ratio is a function of only zooplankton parameters and the phytoplankton abundance. Since the $3-\mathrm{D}$ and box model results agree relatively well, one can conclude that the lateral loss terms affect zooplankton and phytoplankton in a very similar manner, i.e. have only a secondary effect on $Z / P$. In fact, the observation that the 3 -D solutions exhibit generally lower $Z / P$ values at high phytoplankton concentrations and higher $Z / P$ values at low phytoplankton concentrations can largely be interpreted by the impact of the lateral flow present in the 3-D solutions. In the phytoplankton rich nearshore zone, zooplankton appears to grow too slowly to establish tight grazing control on phytoplankton, while lateral transport of the zooplankton into the low phytoplankton offshore zone may lead to an abundance of zooplankton in this region that is above that expected from the local steady-state.

\subsection{Detritus}

Figure 19b shows in more detail the previously noted nearly equal concentration of small detritus and phytoplankton in the 3-D model. This nearly uniform ratio of 1 is not an intrinsic property of our ecosystem, since the box model results show a ratio that starts around 1 , but increases with increasing 
phytoplankton biomass. Therefore, either lateral transport processes or the absence of local steady-state must explain this behavior. We can immediately exclude net divergences by lateral transport as an explanation for the difference between 3-D and the box model, since both constituents have nearly equal net transport divergences, so that this would not affect the small detritus to phytoplankton ratio. This essentially leaves us with the explanation that small detritus does not achieve local steady-state in the 3-D model, i.e. that the production and remineralization of small detritus are not balanced locally. In order to investigate this further, let us first look at the processes that determine the steady-state ratio.

In the offshore region, where the zooplankton population is low, the primary mechanism for the production of small detritus is phytoplankton mortality. Under these conditions, the steady-state of the ratio of small detritus to phytoplankton can be approximated by (see online supplementary material for derivation):

$$
\left(D_{S} / P\right)^{\text {steady-state, low } \mathrm{Z}} \approx \frac{k_{D_{S}}^{\text {remin }}}{8 k^{\text {coag }}}
$$

With our parameter choices the right hand side is 0.75 , as observed in both the 3-D and box model solutions for low phytoplankton concentrations (Figure $19 b)$.

In regions with substantial zooplankton abundance, sloppy feeding and zooplankton mortality become important sources for small detritus. For these conditions, the small detritus to phytoplankton ratio is given by:

$$
\left(D_{S} / P\right)^{\text {steady-state, high } \mathrm{Z}} \approx \sqrt{\frac{\varepsilon_{2}}{k_{\text {coag }}}}-\frac{k_{D_{S}}^{\text {remin }}}{2 k^{\text {coag } P}}
$$


where $\varepsilon_{2}$ is a function that includes several parameters and is slightly dependent on the phytoplankton concentration $P$ (see online supplementary material for definition and the derivation of (22)). For a typical $P$ of $1 \mathrm{mmol} \mathrm{N} \mathrm{m}^{-3}$, $\varepsilon_{2}$ is 0.19 day $^{-1}\left(\mathrm{mmol} \mathrm{m}^{-3}\right)^{-2}$, resulting in a $\left(D_{S} / P\right)^{\text {steady-state, high } \mathrm{Z}}$ value of 3.2 , close to the numerical value computed by the box model.

The timescale to achieve this local steady-state for small detritus is determined by the coagulation and remineralization rate constants. These rate constants are an order of magnitude smaller than those for phytoplankton so that the small detritus to phytoplankton ratio is sensitive to the residence time of near surface waters in a particular region. In the nearshore regions, the time waters spend in the well lit surface region is likely too short to come into local equilibrium with regard to the processes generating small detritus, resulting in the 3-D model consistently having smaller ratios than the box model at high phytoplankton (or total nitrogen) concentrations. In the offshore region, residence times of waters are longer and apparently sufficient to reach a local steady-state, as evidenced by the convergence of the 3-D and box model results. In conclusion, it appears that the nearly constant 1:1 ratio of small detritus and phytoplankton in the 3-D configuration of the model is not an intrinsic property of the ecosystem, but the result of chance.

For large detritus, the difference between the 3-D and box models is even larger, but the same arguments listed above for small detritus are valid here. In fact, they are amplified since the timescale for the formation of large detritus is even longer than that for small detritus. 


\subsection{Nitrate and Ammonium}

The most dramatic differences between the 3-D results and the box model solutions are found for the two limiting nutrients, nitrate and ammonium (Figure 18b). The difference is particularly large for nitrate, which remains very high at high total nitrogen content in the 3 -D configuration, but is drawn down to very low levels in the box model configuration regardless of the total nitrogen content.

The latter behavior can be easily explained by the local steady-state condition for nitrate in the box model, i.e. phytoplankton uptake must be equal to the supply by nitrification and vertical transport/mixing. This condition is only met when nitrate is well below the half-saturation constant for phytoplankton uptake, as phytoplankton otherwise would remove much more nitrate than is being supplied. Evidently, in the 3-D configuration, phytoplankton is much less successful in taking up the supplied nitrate, particularly in the nearshore region, leaving a substantial fraction of the total nitrogen in this pool.

This absence of nearly complete nitrate removal in the nearshore upwelling region of the 3-D model can be explained by considering the nitrate balance in this region. In this region, nitrate far exceeds the half saturation constant for nitrate uptake, $K_{N_{n}}$, i.e. $N_{n}>>K_{N_{n}}$, so that the nitrate balance and hence steady-state nitrate concentration can be approximated by (see online supplementary material for details):

$$
N_{n}^{\text {steady-state }, 3-D} \approx N_{n}^{u p}-\frac{h}{w} \mu_{P}^{\max }(T, I) \cdot P
$$

where $N_{n}^{u p}$ is the nitrate concentration of the upwelling waters, and $h$ is the depth of the surface layer. The term $h / w$ has units of time and can be inter- 
preted as the residence time of surface waters relative to upwelling. This term is small in the nearshore upwelling region, but increases with offshore distance, as $w$ decreases. We thus expect a monotonic decrease of nitrate as a function of offshore distance with a slope that is steeper at high $P$ concentrations, i.e. when total nitrogen is high, becoming less steep as $P$ decreases. These predictions compare very favorably with the $3-\mathrm{D}$ results shown in Figure 18b.

We can thus understand the fundamentally different behavior of nitrate in the 3-D model relative to the box model as primarily reflecting differences in the residence time of waters relative to upwelling. In the box model, this residence time is essentially infinitely long, while surface waters are relatively rapidly moved offshore in the 3-D model, resulting in short residence times in a fixed location along an offshore trajectory. This precludes nitrate from being drawn down to very low levels as is the case in the box model. The same explanation applies to the difference of ammonium between the 3-D and box model solutions.

\subsection{Allocation summary}

The nitrogen allocation to the different ecosystem pools in our dynamic 3-D simulations differs substantially from that predicted by the box model. The primary reason for this difference is that the governing balance in the $3-\mathrm{D}$ model is one of upwelling in the nearshore areas, followed by lateral transport of the upwelled waters offshore, whereas the box model only considers local vertical supply of nutrients and vertical sinking of the produced organic mat-

ter. As a result of this lateral transport, a distinct onshore-offshore gradient exists for the residence time of waters in the surface ocean. The residence times 
in the nearshore regions are short relative to the characteristic equilibration time of the ecosystem, so that most of the ecosystem variables are unable to reach a local steady-state, i.e. being balanced by biological sources and sinks. This effect is strongest for the slowest components of the ecosystem, i.e. the detrital pools, as evidenced by their concentrations being up to an order of magnitude smaller in the 3-D solutions than those predicted by the box model. The effect is also substantial for nitrate, primarily because of its high concentration in the upwelled waters. An important exception is zooplankton, which appears to reach an abundance relative to that of phytoplankton that is generally close to that predicted by local steady-state. This is because both pool sizes start from low levels and grow at similar rates.

\section{Summary and Conclusion}

We have coupled an NPZD-type ecosystem/biogeochemistry model to an eddyresolving 3-D physical model of the California Current System (CCS) in order to study biological-physical interactions in this upwelling dominated region

and how these interactions shape the planktonic ecosystem. Evaluations of the model results with in situ and remote observations of chlorophyll reveal considerable success of this coupled model in capturing the annual mean distribution as well as the mean seasonal cycle, particularly south of Cape Mendocino (about $40.5^{\circ} \mathrm{N}$ ). The most important deficiency in this region is the tendency of the model to overestimate the observed chlorophyll in the eutrophic nearshore region, and to underestimate it in the oligotrophic offshore region. We attribute this deficiency primarily to our use of a single phytoplankton functional group model, which is structurally strongly limited in its 
ability to simultaneously capture these two very different nutrient regimes.

Larger discrepancies exist in the northern part of our domain, where our model systematically underestimates the observed chlorophyll. We attribute this deficiency primarily to our use of monthly mean surface forcing, which leads to an underestimation of upwelling in areas, where it tends to occur more episodically, such as is the case north of Cape Mendocino. This problem is less important further south since upwelling favorable winds persist there over longer periods. Comparisons of the other state variables of the ecosystem model with the often much more limited observations reveal similar agreements and discrepancies.

We conclude that the use of a relatively simple NPZD-type ecosystem model coupled to a high-resolution physical model is adequate for capturing the most important features of the observed ecosystem variations in the CCS. We attribute a substantial fraction of this success to the use of our physical model, which, by resolving the mesoscale, explicitly captures most of the important physical processes in the CCS. The comparison of the model simulated chlorophyll fields also profited markedly by our consideration of a variable chlorophyll-to-carbon ratio as a state variable. A further improvement of our model is the detailed modeling of the detrital pools. The consideration of two size classes of particles turned out to be of critical importance in governing the fate of organic matter produced in the nearshore zone. While most of the large particles are exported vertically, the small detritus particles tend to be exported horizontally. As discussed by Plattner et al. (2005), this leads to a strong decoupling of new and vertical export production in the nearshore region. 
Model deficiencies that need to be addressed are the inability of the ecosystem model to simultaneously represent eutrophic and oligotrophic conditions. At the phytoplankton level, this requires at least the addition of a nano/picophytoplankton group that is adapted to the oligotrophic conditions in the offshore environment. We also need to add grazing control of this nano/picophytoplankton by microzooplankton, since our currently modeled mesozooplankton cannot survive at low phytoplankton concentrations. This may be done by adding an additional zooplankton functional group to the model, by implementing prey switching mechanisms, or by modeling this grazing implicitly. We are in the process of adding such extensions to our ecological model by coupling the multiple phytoplankton functional group model of Moore et al. (2004) to our physical model. Initial analyses of these simulations indicate the expected improvement in this model's ability to capture the onshore-offshore transition of chlorophyll that is more gradual in the observations in comparison to our current results. We anticipate also an improvement in our solutions from a switch in our surface forcing to include synoptic variability. We are also planning to replace our lateral boundary conditions to those provided by a Pacific-wide model, permitting us to consider also interannual to decadal variations, since at least part of the variations in the CCS on these timescales are forced by the lateral boundaries.

The spatial and temporal evolution of phytoplankton growth, and in particular the depth transition of a phytoplankton maximum near the surface in the nearshore region to a deep phytoplankton maximum offshore is controlled in our model by the interaction of light and nutrients. As expected, light limitation dominates at depth, while nutrient limitation dominates in near surface waters. An exception is the nearshore region, where light limits growth 
more strongly than nutrients throughout the water column. Iron limitation, which we have not considered in this study here, could change this conclusion, however.

Our detailed study of how nitrogen is allocated to the various pools in the ecosystem has revealed substantial deviations from those predicted in steadystate by a box model of the upper ocean mixed layer, with nitrate and the two particulate detritus pools differing most strongly. The key reason for these differences is that the residence time of waters along their mean trajectory from the time of upwelling until they arrive far offshore is too short relative to the time the ecosystem needs in order to come to equilibrium. As a result, much of the total nitrogen is still in the initial nitrate pool, while the components that are produced last by the ecosystem, i.e. the two detritus components, are much lower than expected from the local steady-state.

A number of important questions remain unanswered. In particular, we have not yet addressed the rates of primary production and the relative contributions of new and regenerated production, respectively. We also have not studied in detail the fate of this freshly produced organic matter. How much is exported vertically and how much is exported laterally to the offshore region? Another important question is the role of mesoscale dynamics. Is it just a source of variability, or do eddies and other meso- and submesoscale phenomena change the solutions in a fundamental manner? What is the impact of the dynamic biological-physical interactions described here on the cycling of carbon and oxygen? These questions will be addressed in upcoming publications. 


\section{Acknowledgements}

We are indebted to Alexander Shchepetkin, Xavier Capet, and Pierrick Penven for their help and support with ROMS. We thank Francisco Chavez and Baldo Marinovic for sharing their data and for stimulating discussions. The detailed and constructive comments of three anonymous reviewers are greatly appreciated. Most of this work has been made possible by two grants from NASA. Additional support is acknowledged from NSF's ITR program. We are grateful to the National Center for Supercomputing Applications for providing us computer time.

\section{References}

Armstrong, R. A., 2006. Nitrogen allocation and photoacclimation in models of aquatic photosynthesis: Alternative representations based on optimality. Deep-Sea Research II In press.

Blumberg, A. F., Mellor, G. L., 1987. A description of a three-dimensional coastal ocean circulation model. In: Heaps, N. (Ed.), Three Dimensional Ocean Models. American Geophysical Union, p. 208.

Capet, X. J., Marchesiello, P., McWilliams, J. C., 2004. Upwelling response to coastal wind profiles. Geophysical Research Letters 31, L13311, doi:10.1029/2004GL020123.

Carr, M.-E., 2002. Estimation of potential productivity in eastern boundary currents using remote sensing. Deep-Sea Research II 49, 59-80.

Carr, M.-E., Kearns, E. J., 2003. Production regimes in four Eastern Boundary Current systems. Deep-Sea Research II 50, 3199-3221.

Chai, F., Jiang, M., Barber, R. T., Dugdale, R. C., Chao, Y., 2003. In- 
terdecadal variation of the transition zone chlorophyll front: A physicalbiological model simulation between 1960 and 1990. Journal of Oceanography 59, 461-475.

Conkright, M. E., Locarnini, R. A., Garcia, H., Brien, T. O., Boyer, T., Stephens, C., Antonov, J., 2002. World Ocean Atlas 2001: Objective analyses, data statistics, and figures, CD-ROM documentation. Tech. rep., National Oceanographic Data Center, Silver Spring, MD.

Cushing, D. H., Humprey, G. H., Banse, K., Laevastui, T., 1958. Report of the committee on terms and equivalents. Rapports et Procès-verbaux des Réunions du Conseil Permanent International pour l'Exploration de la Mer $144,15-16$.

da Silva, A. M., Young, C. C., Levitus, S., 1994. Atlas of surface marine data 1994. volume 1: Algorithms and procedures. Tech. Rep. NOAA Atlas NESDIS 6, National Oceanic and Atmospheric Administration, Washington, D.C.

DeAngelis, D. L., 1992. Dynamics of Nutrient Cycling and Food Webs. Chapman and Hall, London, 270pp.

Denman, K. L., Abbott, M. R., 1994. Time scales of pattern evolution from cross-spectrum analysis of advanced very high resolution radiometer and coastal zone color scanner imagery. Journal of Geophysical Research 99, $7433-7442$.

Di Lorenzo, E., Miller, A. J., Schneider, N., McWilliams, J. C., 2005. The warming of the California current: Dynamics, thermodynamics and ecosystem implications. Journal of Physical Oceanography 35, 336-362.

DiGiacomo, P., Holt, B., 2001. Satellite observations of small coastal ocean eddies in the Southern California Bight. Journal of Geophysical Research $106,22,521-22,543$. 
Doney, S. C., 1999. Major challenges confronting marine biogeochemical modeling. Global Biogeochemical Cycles 13, 705-714.

Doney, S. C., Glover, D. M., Najjar, R. G., 1996. A new coupled, onedimensional biological-physical model for the upper ocean: Applications to the JGOFS Bermuda Atlantic Time-series Study (BATS) site. Deep-Sea Research II 43, 591-624.

Dong, C., McWilliams, J. C., 2006. A numerical study of island wakes in the Southern California Bight. Continental Shelf Research Submitted.

Dugdale, R. C., Goering, J. J., 1967. Uptake of new and regenerated forms of nitrogen in primary productivity. Limnology and Oceanography 12, 196206.

Eppley, R. W., 1972. Temperature and phytoplankton growth in the sea. Fishery Bulletin 70, 1063-1085.

Eppley, R. W. (Ed.), 1986. Plankton Dynamics of the Southern California Bight. Springer Verlag, New York, 383pp.

Eppley, R. W., Renger, E. H., Betzer, P. R., 1983. The residence time of particulate organic carbon in the surface layer of the ocean. Deep-Sea Research 30, 311-323.

Evans, G. T., Parslow, J. S., 1985. A model of annual plankton cycles. Biological Oceanography 3, 327-347.

Fasham, M. J. R., Baliño, B. M., Bowles, M. C., 2001. A new vision of ocean biogeochemistry after a decade of the Joint Global Ocean Flux Study (JGOFS). Ambio Special Report No. 10, 4-30.

Fasham, M. J. R., Ducklow, H. W., McKelvie, S. M., 1990. A nitrogen-based model of plankton dynamics in the oceanic mixed layer. Journal of Marine Research 48, 591-639.

Fasham, M. J. R., Sarmiento, J. L., Slater, R. D., Ducklow, H. W., Williams, 
R., 1993. Ecosystem behavior at Bermuda station "S" and ocean weather station "India": A general circulation model and observational analysis. Global Biogeochemical Cycles 7, 379-415.

Gardner, W. D., Mishonov, A. V., Richardson, M. J., 2006. Global POC concentrations from in-situ and satellite data. Deep-Sea Research II In press.

Geider, R. J., MacIntyre, H. L., Kana, T. M., 1997. Dynamic model of phytoplankton growth and acclimation: responses of the balanced growth rate and the chlorophyll $a$ :carbon ratio to light, nutrient-limitation and temperature. Marine Ecology Progress Series 148, 187-200.

Geider, R. J., Platt, T., Raven, J. A., 1986. Size dependence of growth and photosynthesis in diatoms: a synthesis. Marine Ecology Progress Series 30, 93-104.

Gregg, W. W., Ginoux, P., Schopf, P. S., Casey, N. W., 2003. Phytoplankton and iron: validation of a global three-dimensional ocean biogeochemical model. Deep-Sea Research II 50, 3143-3169.

Hood, R. R., Christian, J. R., 2006. Ocean N-cycle modeling. In: Capone, D. G., Bronk, D. A., Mulholland, M. R., Carpenter, E. J. (Eds.), Nitrogen in the Marine Environment. Academic Press, submitted.

Hutchins, D. A., Bruland, K. W., 1998. Iron-limited diatom growth and Si:N uptake ratios in a coastal upwelling regime. Nature 393, 561-564.

Hutchins, D. A., DiTullio, G. R., Zhang, Y., Bruland, K. W., 1998. An iron limitation mosaic in the California upwelling regime. Limnology and Oceanography $43,1-37-1054$.

Huyer, A., 1983. Coastal upwelling in the California Current System. Progress in Oceanography 12, 259-284.

Ianson, D., Allen, S. E., 2002. A two-dimensional nitrogen and carbon flux model in a coastal upwelling region. Global Biogeochemical Cycles 16, 
10.1029/2001GB001451.

Koné, V., Machu, E., Penven, P., Andersen, V., Garçon, V., Fréon, P., Demarcq, H., 2005. Modeling the primary and secondary productions of the southern Benguela upwelling system: A comparative study through two biogeochemical models. Global Biogeochemical Cycles 19, GB4021, doi:10.1029/2004GB002427.

Large, W. G., Gent, P. R., 1999. Validation of vertical mixing in an equatorial ocean model using large eddy simulations and observations. Journal of Physical Oceanography 29, 449-464.

Large, W. G., McWilliams, J. C., Doney, S. C., 1994. Oceanic vertical mixing: A review and a model with a nonlocal boundary layer parameterization. Reviews of Geophysics 32, 363-403.

Li, X., Chao, Y., McWilliams, J. C., Fu, L.-L., 2001. A comparison of two vertical mixing schemes in a Pacific Ocean general circulation model. Journal of Climate 14, 1377-1398.

Lima, I. D., Doney, S. C., 2004. A three-dimensional, multinutrient, and sizestructured ecosystem model for the North Atlantic. Global Biogeochemical Cycles 18, GB3019, doi:10.1029/2003GB002146.

Liu, K. K., Atkinson, L., Chen, C.-T. A., Gao, S., Hall, J., MacDonald, R. W., Talaue-McManus, L., Quiñones, R., 2000. Exploring continental margin carbon fluxes on a global scale. Eos Transactions AGU 81, 641-644.

Marchesiello, P., McWilliams, J. C., Shchepetkin, A. F., 2001. Open boundary conditions for long-term integration of regional oceanic models. Ocean Modelling 3, 1-20.

Marchesiello, P., McWilliams, J. C., Shchepetkin, A. F., 2003. Equilibrium structure and dynamics of the California Current system. Journal of Physical Oceanography 33, 753-783. 
McGillicuddy, D. J., Anderson, L. A., Doney, S. C., Maltrud, M. E., 2003. Eddy-driven sources and sinks of nutrients in the upper ocean: Results from a $0.1^{\circ}$ resolution model of the North Atlantic. Global Biogeochemical Cycles 17, 1035, doi:10.1029/2002GB001987.

Moisan, J. R., Hofmann, E. E., Haidvogel, D. B., 1996. Modeling nutrient and plankton processes in the California coastal transition zone. 2. A threedimensional physical-bio-optical model. Journal of Geophysical Research 101, 22677-22691.

Moisan, J. R., Miller, A. J., Lorenzo, E. D., Wilkin, J., 2005. Modeling and data assimilation. In: Miller, R. L., Castillo, C. E. D., McKee, B. A. (Eds.), Remote Sensing of Coastal Aquatic Environments. Springer Verlag, New York, Ch. 10, pp. 229-257.

Moloney, C. L., Field, J. G., 1991. The size-based dynamics of plankton food webs. 1. A simulation model of carbon and nitrogen flows. Journal of Plankton Research 13, 1003-1038.

Monod, J., 1949. The growth of bacterial cultures. Annual Review of Microbiology 3, 371-394.

Moore, J. K., Doney, S. C., Lindsay, K., 2004. Upper ocean ecosystem dynamics and iron cycling in a global three-dimensional model. Global Biogeochemical Cycles 18, GB4028, doi:10.1029/2004GB002220.

Muller-Karger, F. E., Varela, R., Thunell, R., Luerssen, R., Hu, C., Walsh, J. J., 2005. The importance of continental margins in the global carbon cycle. Geophysical Research Letters 32, L01602, doi:10.1029/2004GL021346.

O’Brien, T. D., Conkright, M., Boyer, T., Stephens, C., Antonov, J. I., Locarnini, R., Garcia, H., 2002. World Ocean Atlas 2001, Volume 5: Plankton. NOAA Atlas NESDIS 53, NOAA, NESDIS, U.S. Government Printing Office, Washington, D.C. 
Olivieri, R. A., Chavez, F. P., 2000. A model of plankton dynamics for the coastal upwelling system of Monterey Bay, California. Deep-Sea Research II $47,1077-1106$.

Oschlies, A., 2001. Model-derived estimates of new production: new results point toward lower values. Deep-Sea Research II 48, 2173-2197.

Oschlies, A., Garçon, V., 1998. Eddy-induced enhancement of primary production in a model of the North Atlantic Ocean. Nature 394, 266-269.

Parker, R. A., 1993. Dynamic models for ammonium inhibition of nitrate uptake by phytoplankton. Ecological Modelling 66, 113-120.

Pennington, J. T., Chavez, F. P., 2000. Seasonal fluctuations of temperature, salinity, nitrate, chlorophyll and primary production at station H3/M1 over 1989-1996 in Monterey Bay, California. Deep-Sea Research II 47, 947-973.

Penven, P., Debreu, L., Marchesiello, P., McWilliams, J. C., 2006. Evaluation and application of the ROMS 1-way embedding procedure to the central California upwelling system. Ocean Modelling 12, 157-187.

Penven, P., Roy, C., Brundrit, G. B., Colin de Verdiere, A., Freon, P., Johnson, A. S., Lutjeharms, J. R. E., Shillington, F., 2001. A regional hydrodynamic model of upwelling in the Southern Benguela. South African Journal of Science 97, 1-4.

Platt, T., Bird, D., Sathyendranath, S., 1991. Critical depth and marine primary production. Proceedings of the Royal Society London B 246, 205-217.

Plattner, G.-K., Gruber, N., Frenzel, H., McWilliams, J. C., 2005. Decoupling marine export production from new production. Geophysical Research Letters 32, L11612, doi:10.1029/2005GL022660.

Roemmich, D., McGowan, J., 1995. Climatic warming and the decline of zooplankton in the California Current. Science 267, 1324-1326.

Roman, M. R., Adolf, H. A., Landry, M. R., Madin, L. P., Steinberg, D. K., 
Zhang, X., 2002. Estimates of oceanic mesozooplankton production: a comparison using the Bermuda and Hawaii time-series data. Deep-Sea Research II 49, 175-192.

Sarmiento, J. L., Gruber, N., 2006. Ocean Biogeochemical Dynamics. Princeton University Press, Princeton, NJ, 464pp.

Sarmiento, J. L., Slater, R. D., Fasham, M. J. R., Ducklow, H. W., Toggweiler, J. R., Evans, G. T., 1993. A seasonal three-dimensional ecosystem model of nitrogen cycling in the North Atlantic euphotic zone. Global Biogeochemical Cycles 7, 417-450.

Shchepetkin, A. F., McWilliams, J. C., 2005. The regional oceanic modeling system (ROMS): a split-explicit, free-surface, topography-followingcoordinate oceanic model. Ocean Modelling 9, 347-404.

Siegel, D., Doney, S. C., Yoder, J. A., 2002. The North Atlantic spring phytoplankton bloom and Sverdrup's critical depth hypothesis. Science 296, $730-733$.

Slagstad, D., Wassmann, P., 2001. Modelling the 3-D carbon flux across the Iberian margin during the upwelling season in 1998. Progress in Oceanography $51,467-497$.

Smith, E. L., 1936. Photosynthesis in relation to light and carbon dioxide. Proceedings of the National Academy of Sciences 22, 504-511.

Smith, S. V., Hollibaugh, J. T., 1993. Coastal metabolism and the oceanic organic carbon balance. Reviews of Geophysics 31, 75-89.

Song, Y. T., Haidvogel, D., 1994. A semi-implicit ocean circulation model using a generalized topography-following coordinate system. Journal of Computational Physics 115, 228-244.

Spitz, Y. H., Allen, J. S., Gan, J., 2005. Modeling of ecosystem processes on the Oregon shelf during the 2001 summer upwelling. Journal of Geophysical 
Research 110, CS1017, doi:10.1029/2005JC002870.

Spitz, Y. H., Newberger, P. A., Allen, J. S., 2003. Ecosystem response to upwelling off the Oregon coast: Behavior of three nitrogen-based models. Journal of Geophysical Research 108, 3062, doi:10.1029/2001JC001181.

Steele, J. H., 1974. The structure of marine ecosystems. Harvard University Press, Cambridge, MA, 128 pp.

Sverdrup, H. U., 1953. On conditions for the vernal blooming of phytoplankton. Journal du Conseil Permanent International pour l'Exploration de la Mer 18, 287-295.

Taylor, K. E., 2001. Summarizing multiple aspects of model performance in a single diagram. Journal of Geophysical Research 106, 7183-7192.

Thomas, H., Bozec, Y., Elkalay, K., de Baar, H. J. W., 2004. Enhanced open ocean storage of $\mathrm{CO}_{2}$ from shelf sea pumping. Science 304, 1005-1008.

Toole, D. A., Siegel, D. A., 2001. Modes and mechanisms of ocean color variability in the Santa Barbara Channel. Journal of Geophysical Research 106, $26985-27000$.

Tsunogai, S., Watanabe, S., Sato, T., 1999. Is there a "continental shelf pump" for the absorption of atmospheric $\mathrm{CO}_{2}$ ? Tellus Series B 51, 701-712.

Walsh, J. J., 1975. A spatial simulation of the Peru upwelling system. DeepSea Research 22, 201-236.

Walsh, J. J., 1991. Importance of continental margins in the marine biogeochemical cycling of carbon and nitrogen. Nature 350, 53-55.

Walsh, J. J., Dugdale, R. C., 1971. A simulation model of the nitrogen flow in the Peruvian upwelling system. Investigacion Pesquera 35, 309-330.

Wollast, R., 1991. The coastal organic carbon cycle: Fluxes, sources and sinks. In: Mantoura, R., Martin, J.-M., Wollast, R. (Eds.), Ocean Margin Processes in Global Change. John Wiley, New York, pp. 365-381. 
Wollast, R., 1998. Evaluation and comparison of the global carbon cycle in the coastal zone and in the open ocean. In: Brink, K. H., Robinson, A. R. (Eds.), The Sea: The global coastal ocean. Vol. 10. John Wiley \& Sons, New York, Ch. 9, pp. 213-252.

Wroblewski, J. S., 1977. A model of phytoplankton plume formation during variable Oregon upwelling. Journal of Marine Research 35, 357-394. 


\section{$7 \quad$ Figure captions and table}

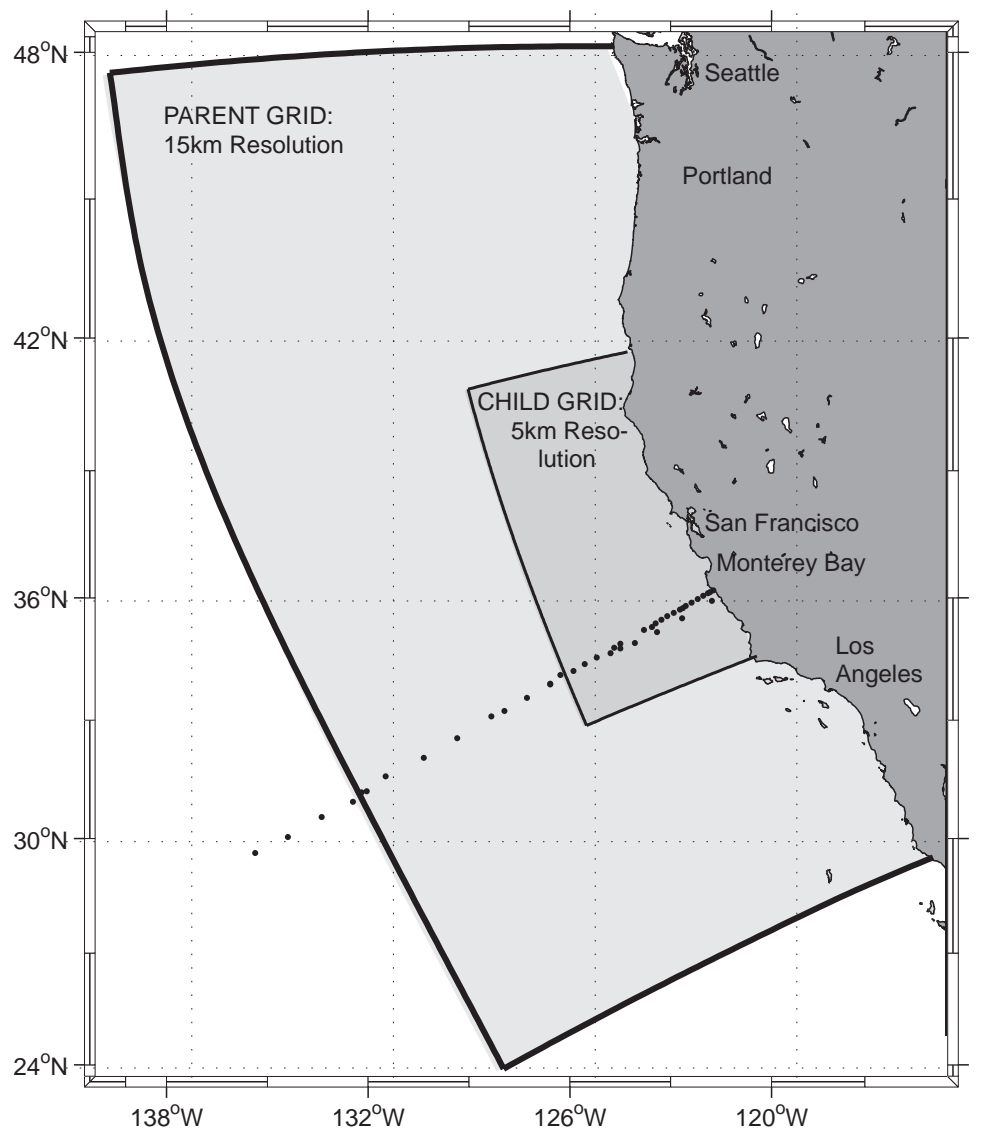

Fig. 1. Map of the model domain. The outer line demarcates the domain of the parent grid, which has a horizontal resolution of about $15 \mathrm{~km}$. The model thus encompasses the entire U.S. west coast and has an alongshore extent of about 2100 $\mathrm{km}$ and an offshore extent of about $1300 \mathrm{~km}$. The inner line shows the domain of the child grid that has a horizontal resolution of about $5 \mathrm{~km}$. Also shown as points are the station locations of CalCOFI line 70 that we use for comparing model results with in situ observations. 


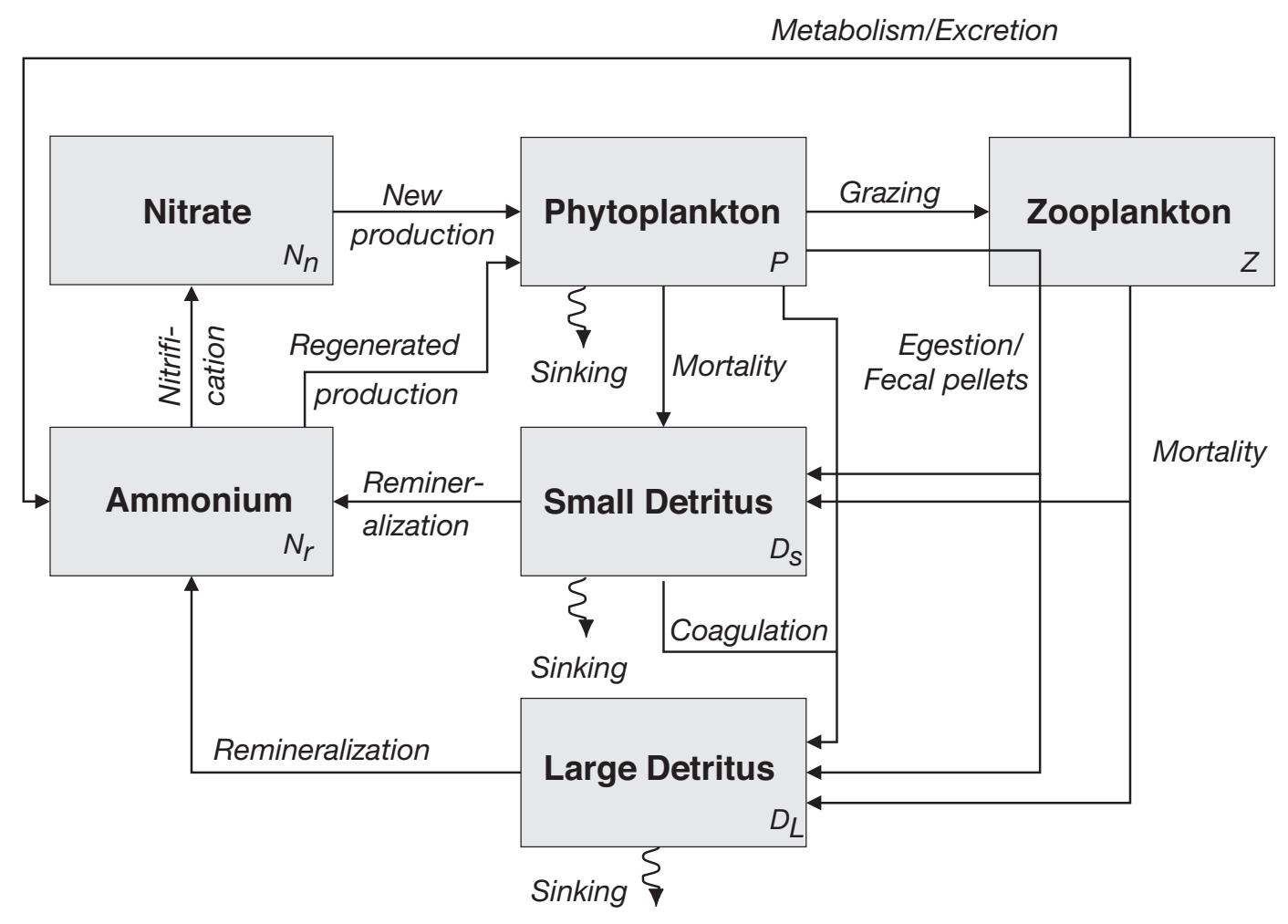

Fig. 2. Flow diagram of the ecological-biogeochemical NPZD-type model. Boxes represent the state variables of the model, expressed in terms of nitrogen concentration, while the arrows show the processes that transform nitrogen from one state variable to another. Not shown is the dynamic chlorophyll-to-carbon ratio, $\theta$, of phytoplankton. 

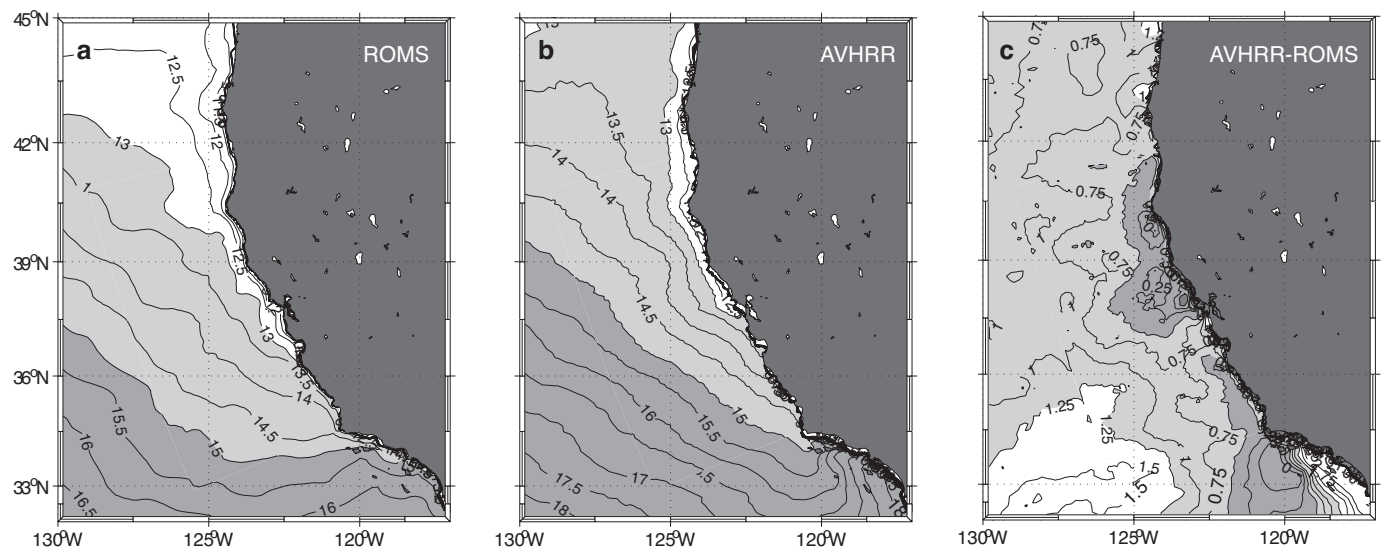

Fig. 3. Comparison of annual mean SST between (a) the ROMS model in its USWC $15+5 \mathrm{~km}$ configuration, (b) remote sensing observations based on AVHRR, and (c) difference between AVHRR and ROMS (AVHRR-ROMS). The modeled annual mean SST is the average of model years 6 through 10 of the $15+5 \mathrm{~km}$ configuration, while the observed annual mean is based on the climatology for the years 1997 2002. 

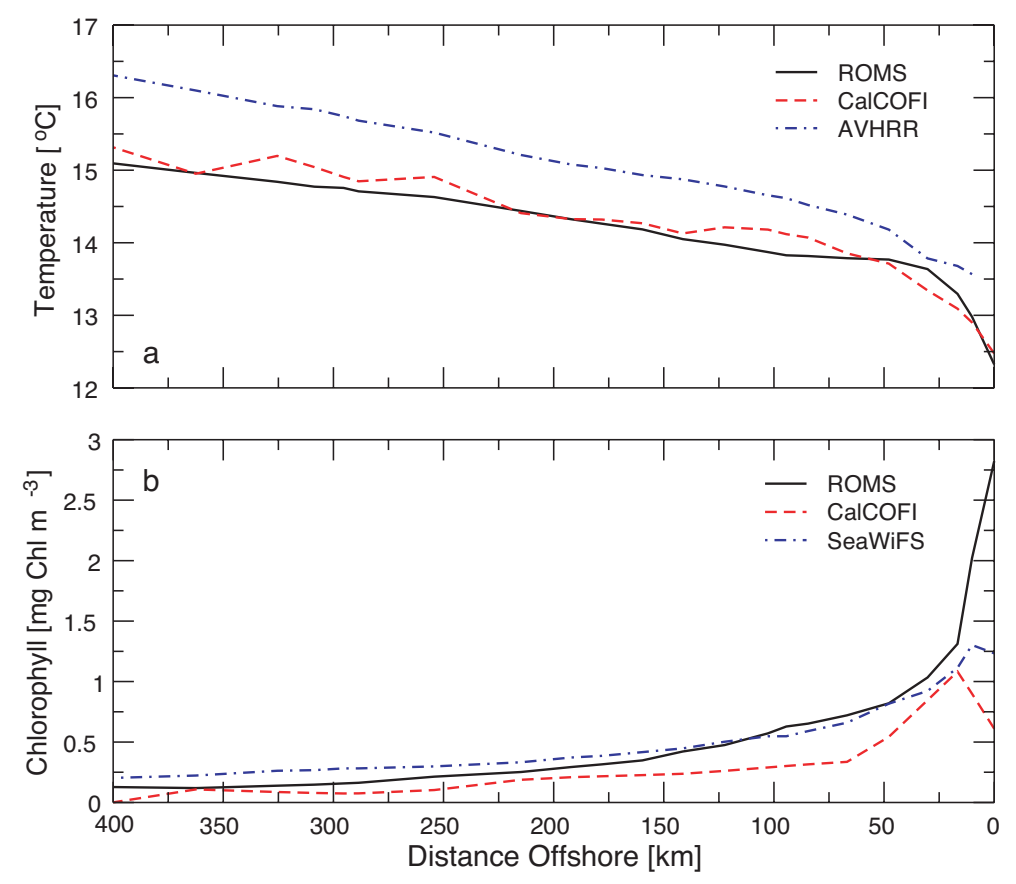

Fig. 4. Comparison of surface properties as a function of offshore distance along CalCOFI line 70. a) Comparison of sea surface temperature (SST) between ROMS, AVHRR, and CalCOFI. b) Comparison of near-surface chlorophyll between ROMS, SeaWiFS, and CalCOFI. CalCOFI line 70 starts at about $36^{\circ} \mathrm{N}, 122^{\circ} \mathrm{W}$ at the California coast just south of Monterey Bay and extends out for nearly $700 \mathrm{~km}$. See Figure 1 for exact locations of stations. 

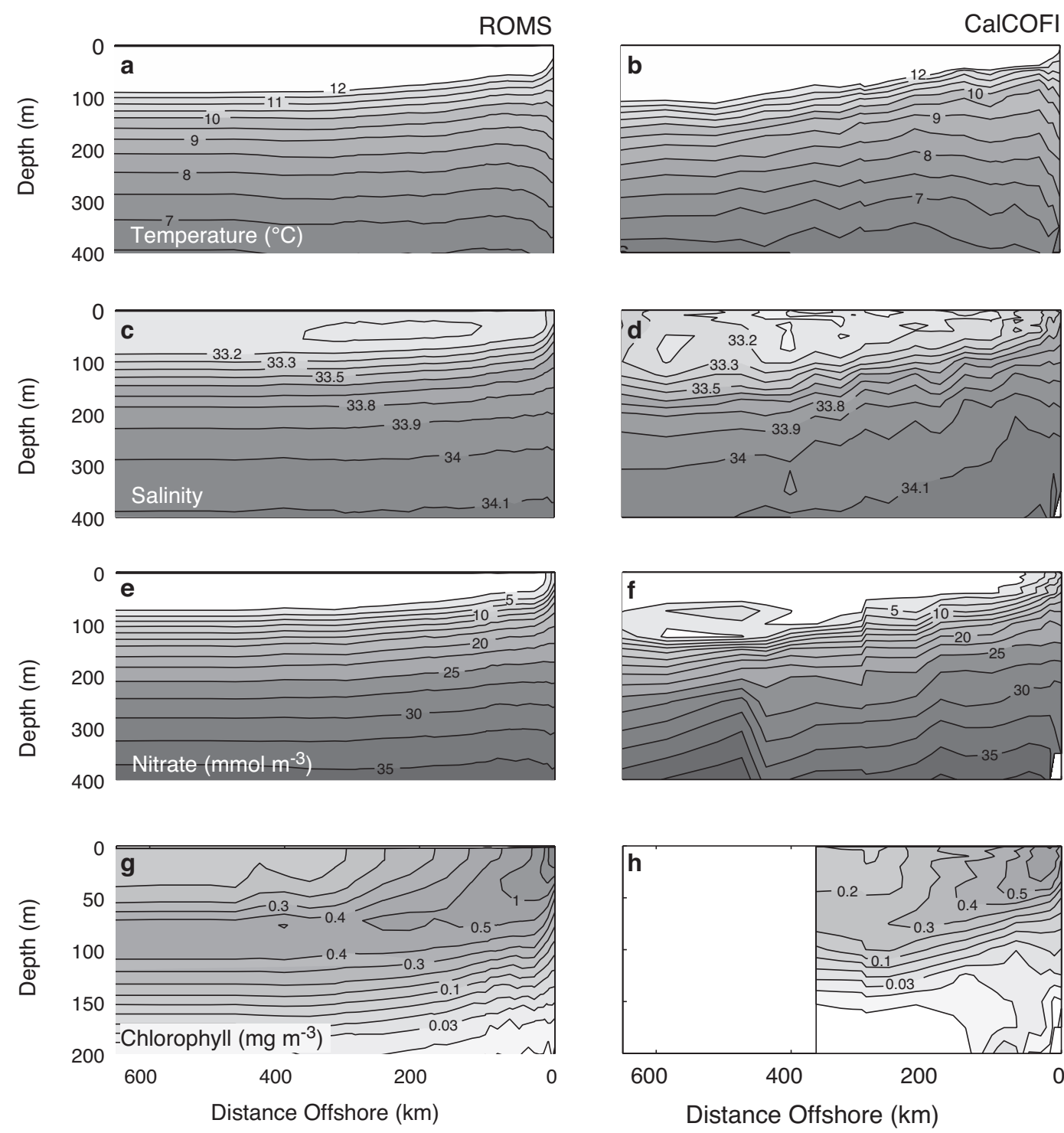

Fig. 5. Vertical sections along CalCOFI line 70 (see Figure 1 for location) showing model results (left columns), and observed quantities (right columns) for the annual mean. (a) and (b) Modeled and observed temperature $\left({ }^{\circ} \mathrm{C}\right)$; (c) and (d) modeled and observed salinity; (e) and (f) modeled and observed nitrate concentration (mmol $\left.\mathrm{m}^{-3}\right) ;(\mathrm{g})$ and $(\mathrm{h})$ modeled and observed chlorophyll-a (mg Chl-a $\mathrm{m}^{-3}$ ). 

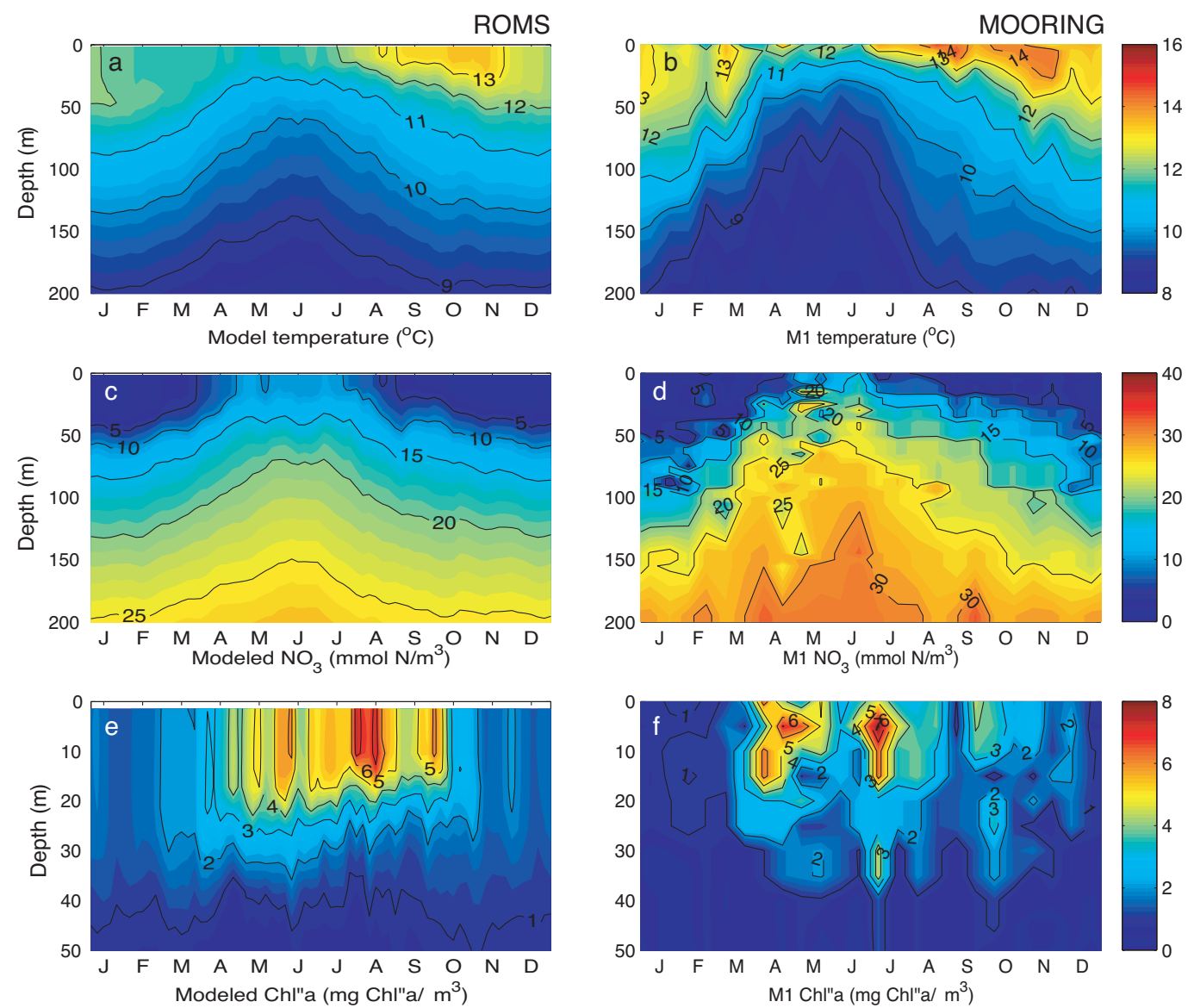

Fig. 6. Comparison of the modeled and observed climatological annual cycle of temperature (a and b), nitrate (c and d), and chlorophyll (e and f) at the M1/H3 mooring site in Monterey Bay. Observations are from Pennington and Chavez (2000). 


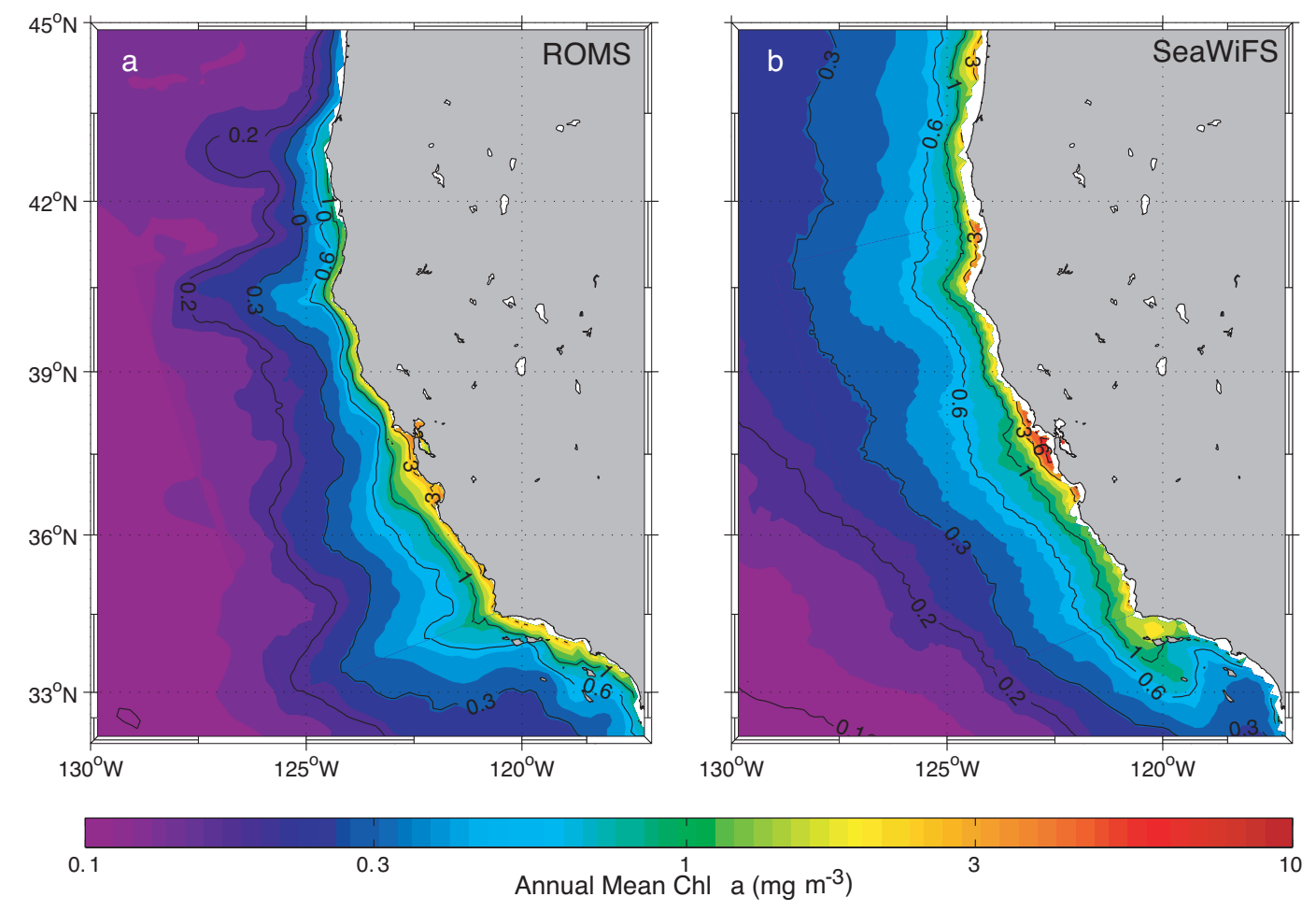

Fig. 7. Comparison of (a) modeled and (b) observed annual mean chlorophyll concentration in near surface waters. The model fields are 5-year averages of the surface fields. The observations are based on SeaWiFS, averaged over the period from 1997 to 2002 (see text for details). 

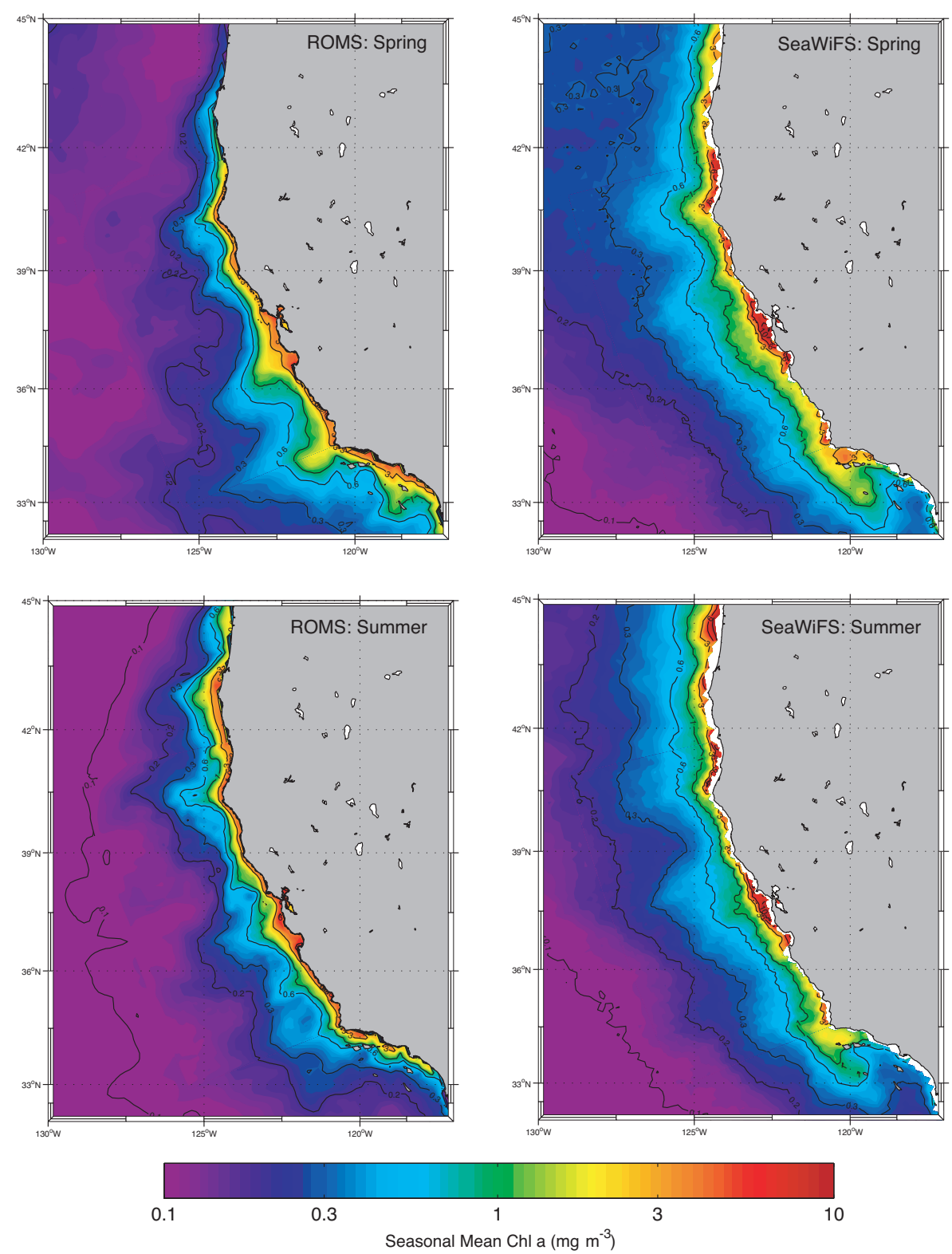

Fig. 8. As Figure 7, except for individual seasons. Spring: April-June; Summer: July-September; Fall: October-December; Winter: January-March 

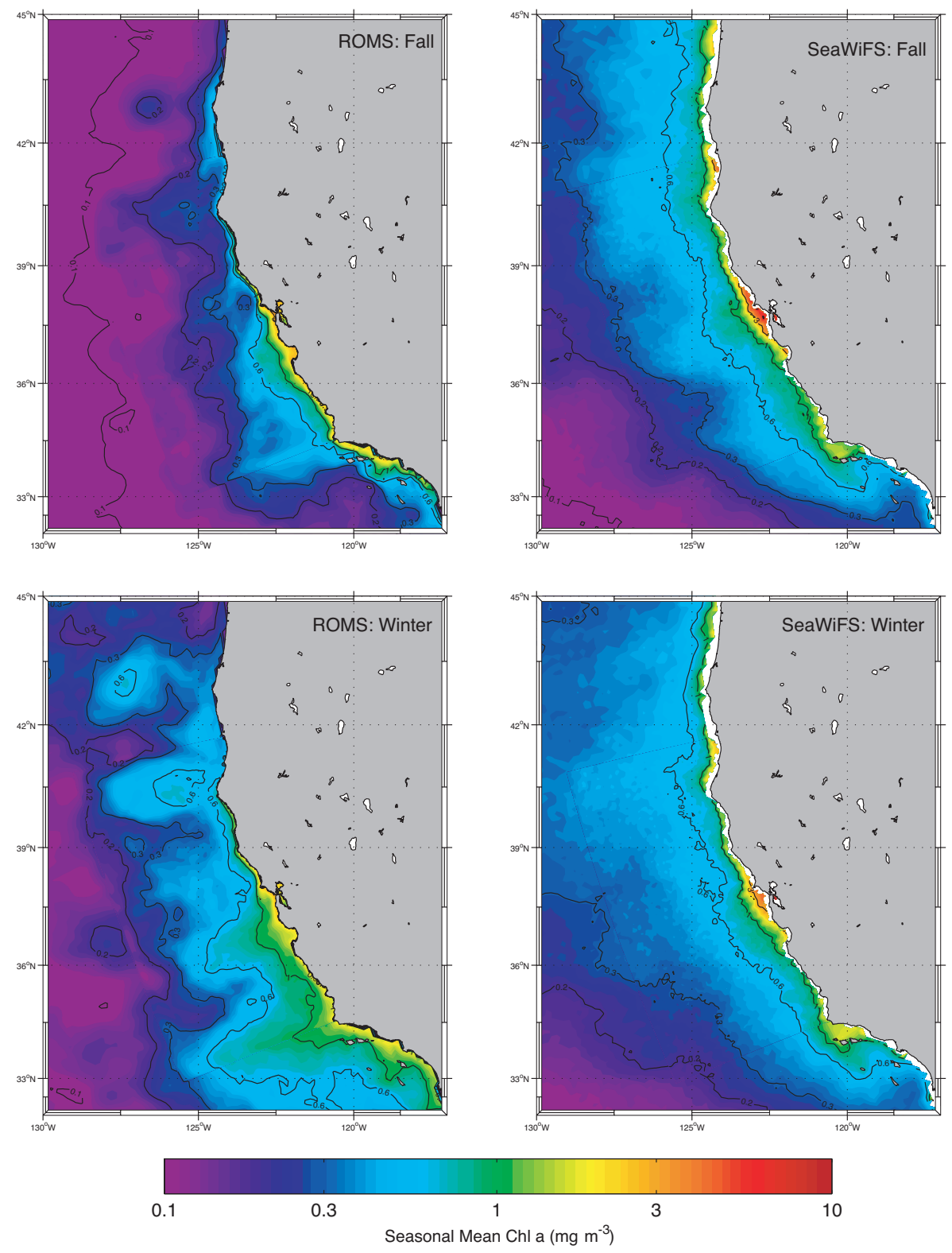

Fig. 8. Cont. 

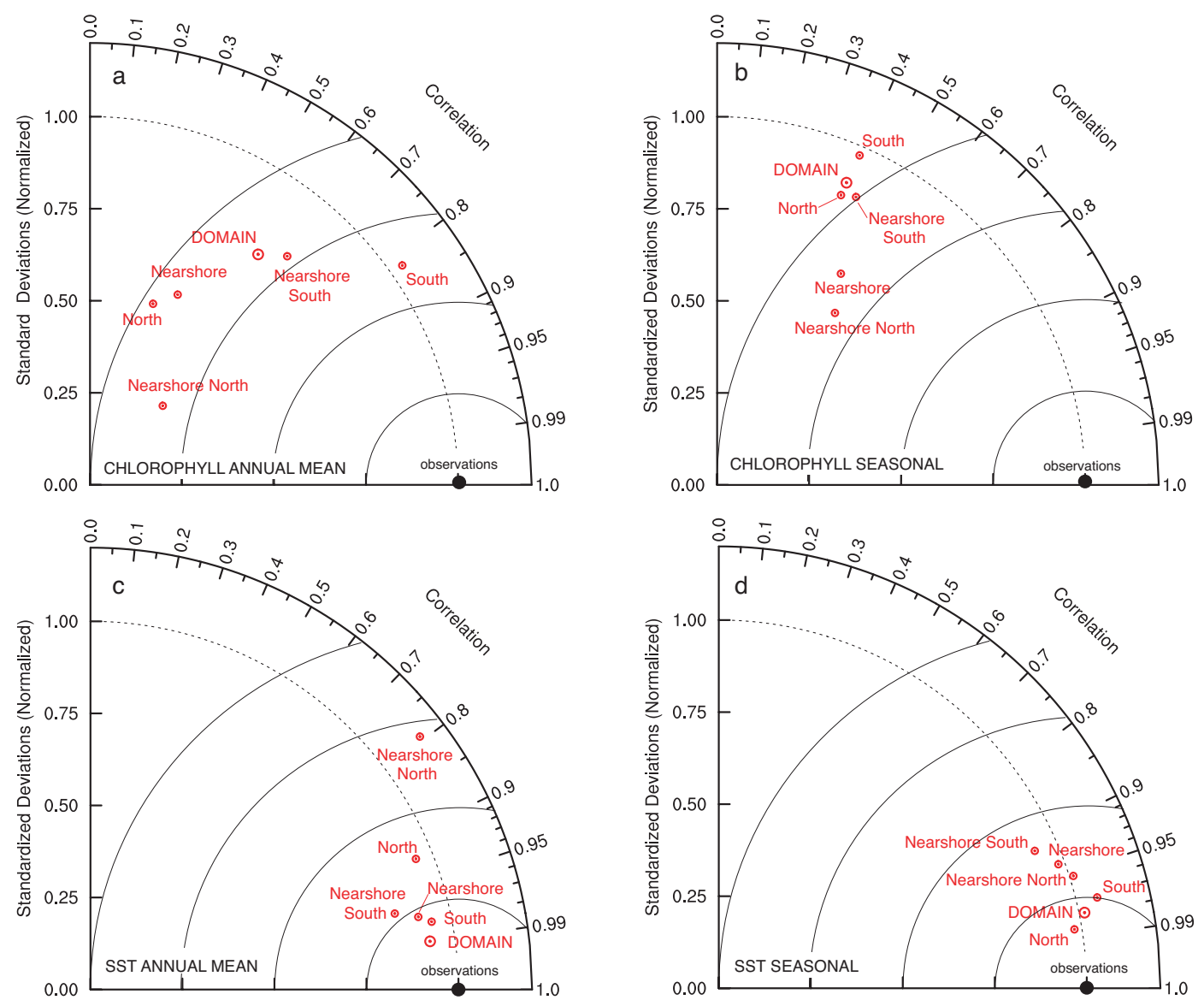

Fig. 9. Taylor diagrams of model simulated chlorophyll (a-b) and Sea Surface Temperature (SST) (c-d) in comparison to observed estimates derived from SeaWiFS (chlorophyll) and AVHRR (SST). Annual mean comparisons are plotted in (a) and (c), while (b) and (d) show the seasonal components, computed by subtracting at each grid point the annual mean from the monthly means. Each panel shows separately the results for the entire model domain (DOMAIN), for the region north and south of Cape Mendocino $\left(40.5^{\circ} \mathrm{N}\right)$ (North and South), for the $100 \mathrm{~km}$ wide nearshore region (Nearshore), and for this nearshore region divided into the region north and south of Cape Mendocino (Nearshore North and Nearshore South). The root mean square (RMS) misfit between the model and the observational estimates is given by the distance between the model point and the observation point indicated by the filled circle on the abscissa. 

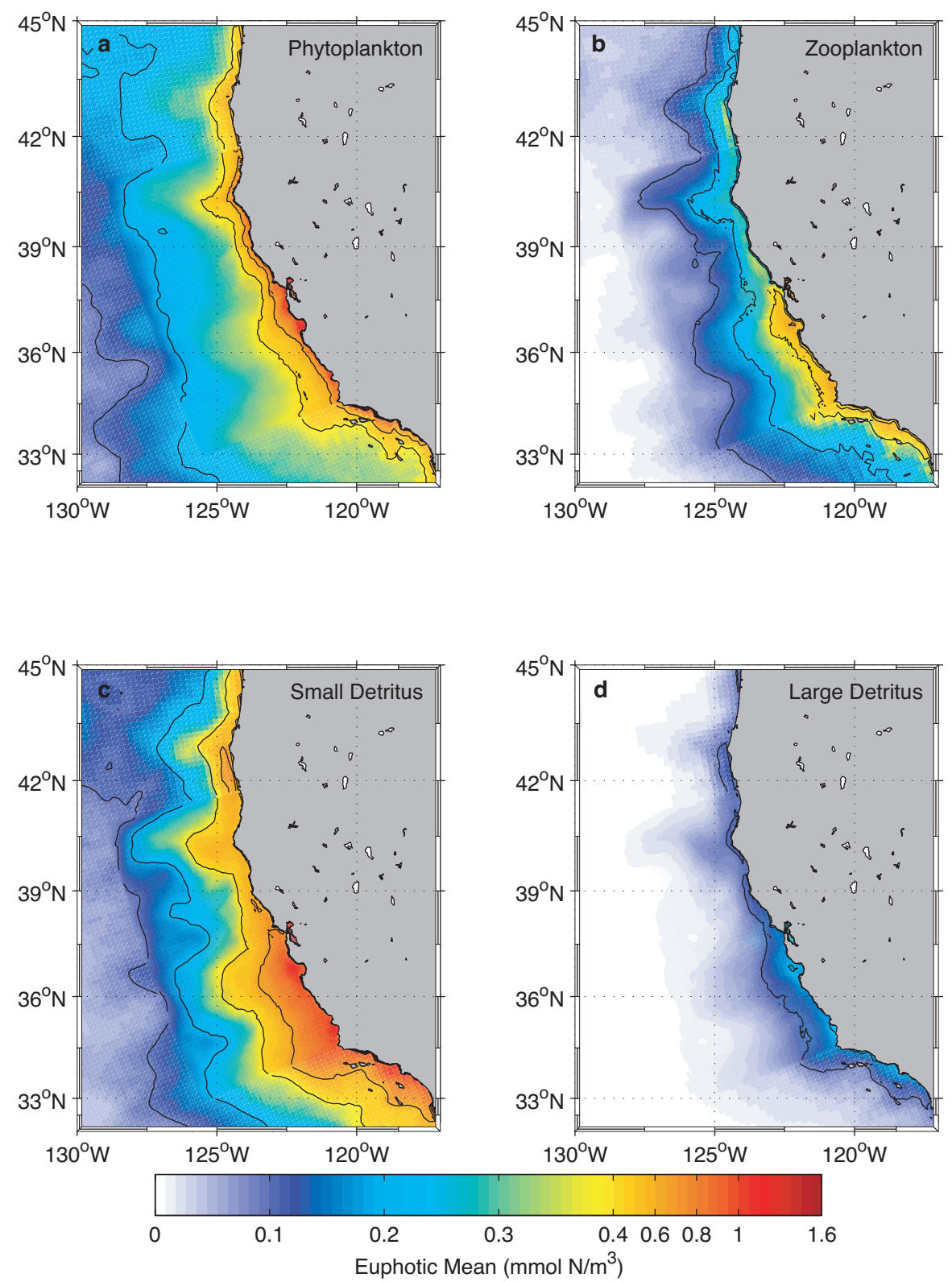

Fig. 10. Maps of the euphotic mean standing stocks for (a) phytoplankton, (b) zooplankton, (c) small detritus, and (d) large detritus. All properties are 5-year annual averages in units of mmol $\mathrm{N} \mathrm{m}^{-3}$. 

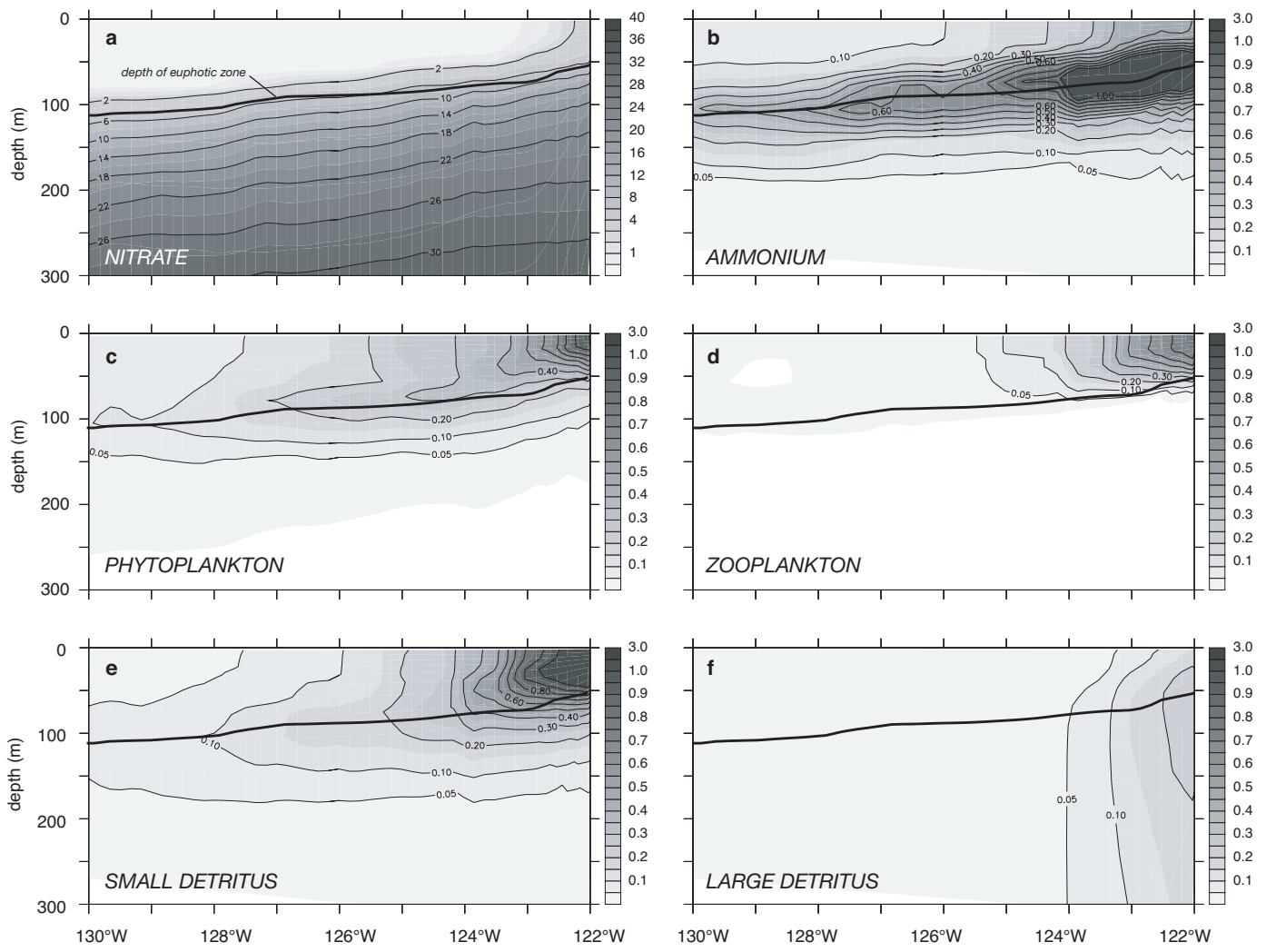

Fig. 11. Offshore vertical sections of annual mean ecosystem and biogeochemical properties across the central California upwelling system. (a) Nitrate, (b) ammonium, (c) phytoplankton, (d) zooplankton, (e) small detritus, and (f) large detritus. All properties are in units of mmol $\mathrm{N} \mathrm{m}^{-3}$. The section starts at about $36.5^{\circ} \mathrm{N}$, $122^{\circ} \mathrm{W}$ and extends to $33.5^{\circ} \mathrm{N}, 130^{\circ} \mathrm{W}$. The thick line indicates the annual mean depth of the $1 \%$ light level, used here as the definition for the depth of the euphotic zone. 

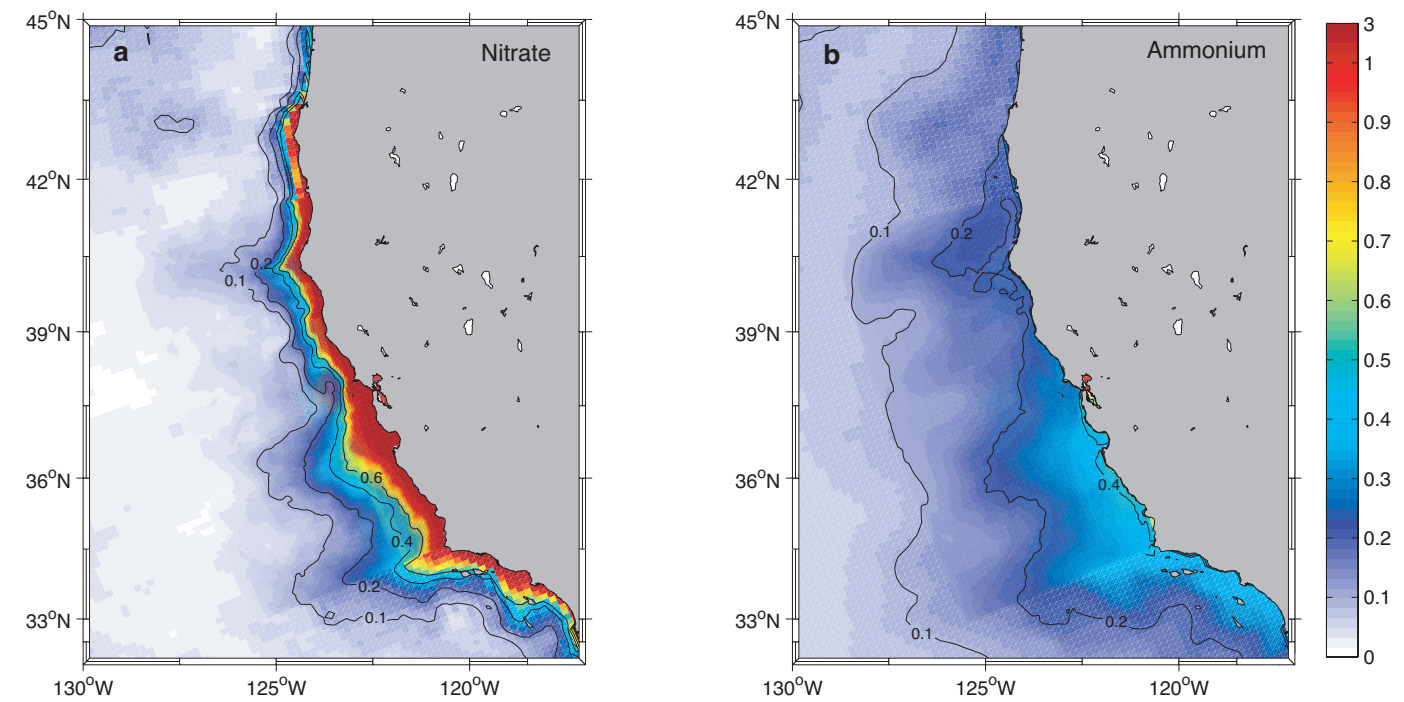

Fig. 12. Maps of the annual mean surface concentration of (a) nitrate, and (b) ammonium in mmol $\mathrm{N} \mathrm{m}^{-3}$. 

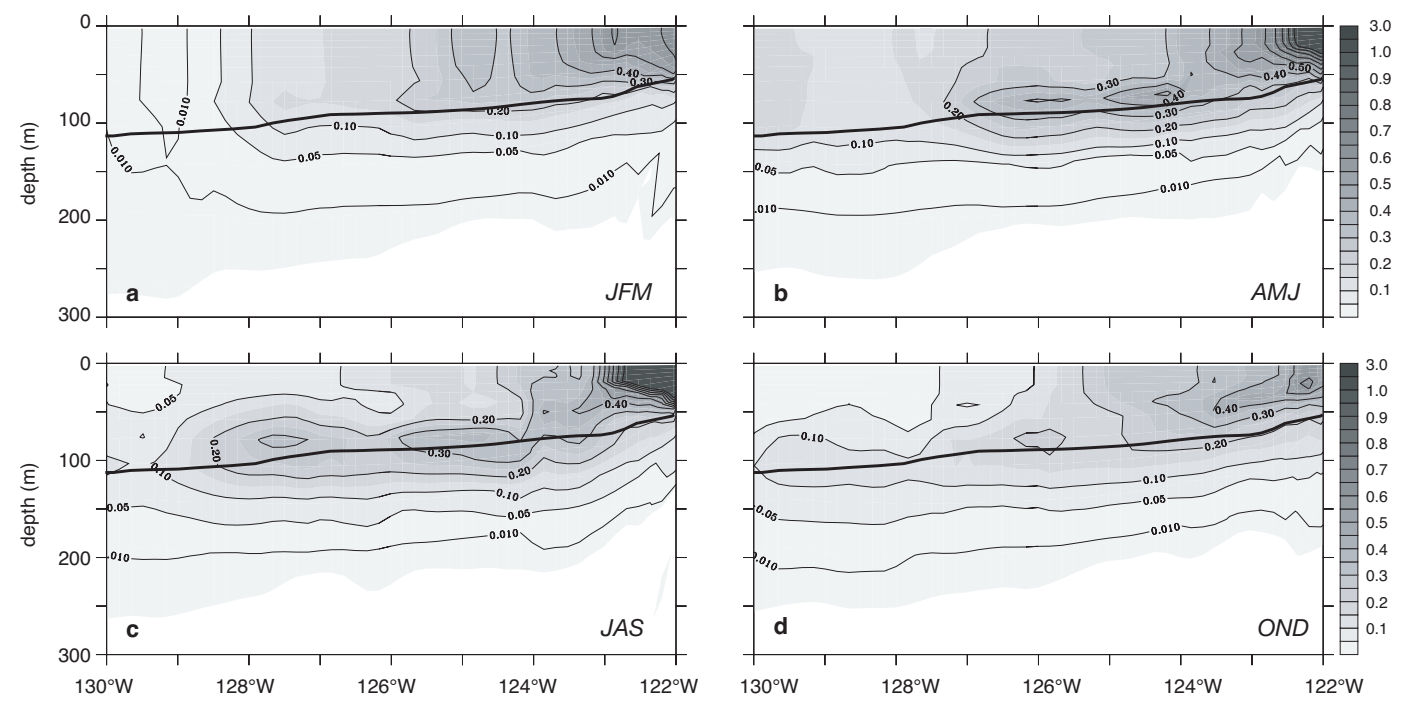

Fig. 13. Seasonal evolution of phytoplankton biomass in mmol $\mathrm{N} \mathrm{m}^{-3}$ along an offshore vertical section across the central California upwelling system. (a) January - March, (b) April - June, (c) July - September, and (d) October - December. The thick line indicates the annual mean depth of the $1 \%$ light level. 

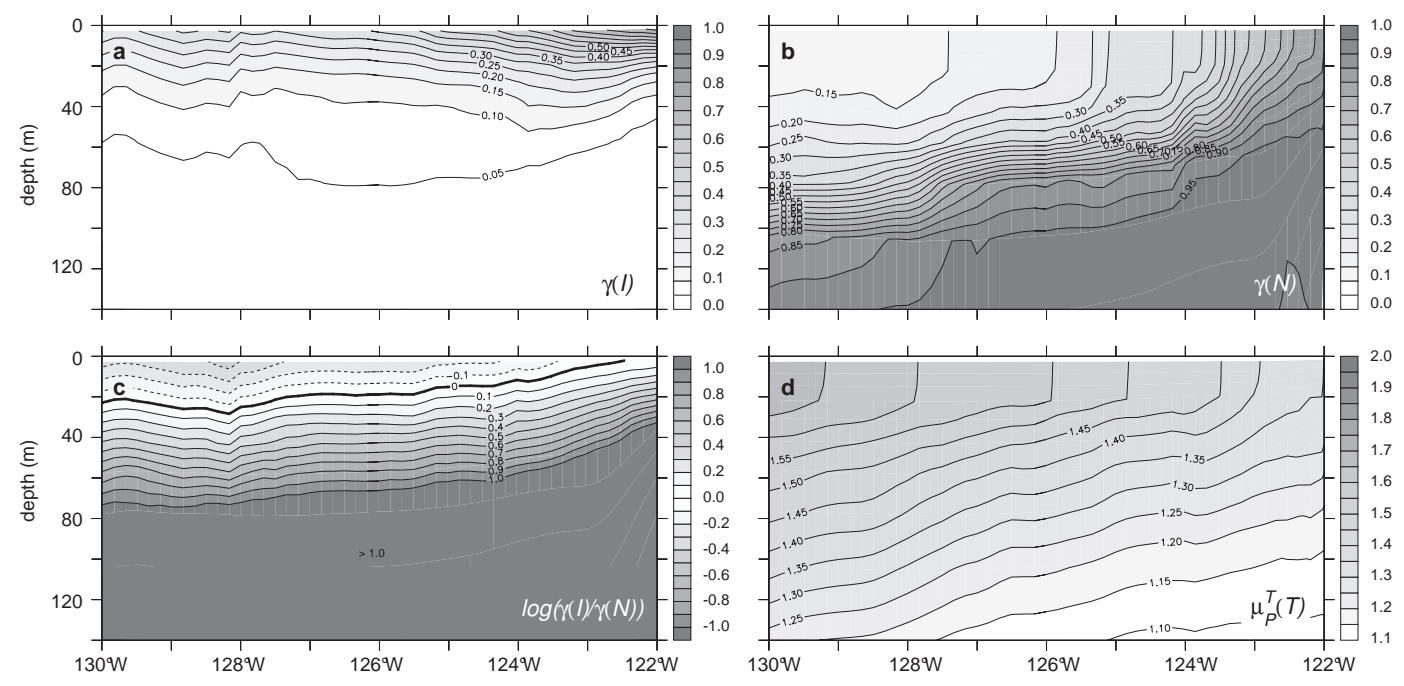

Fig. 14. Offshore vertical sections of the factors that control phytoplankton growth across the central California upwelling system. (a) the light limiting factor, $\gamma(I)$, (b) the nutrient limiting factor, $\gamma\left(N_{n}, N_{r}\right)$, (c) the logarithm of the ratio of the nutrient and light limiting factors, i.e. $\log \left(\gamma\left(N_{n}, N_{r}\right) / \gamma(I)\right)$, and (d) the temperature dependent maximum growth rate, $\mu_{P}^{T}(T)$ in units of day ${ }^{-1}$. In (c) negative values indicate that nutrient availability is the proximate factor limiting phytoplankton growth, while positive values indicate that light is the proximate factor limiting phytoplankton growth. All panels show 5-year annual mean values.
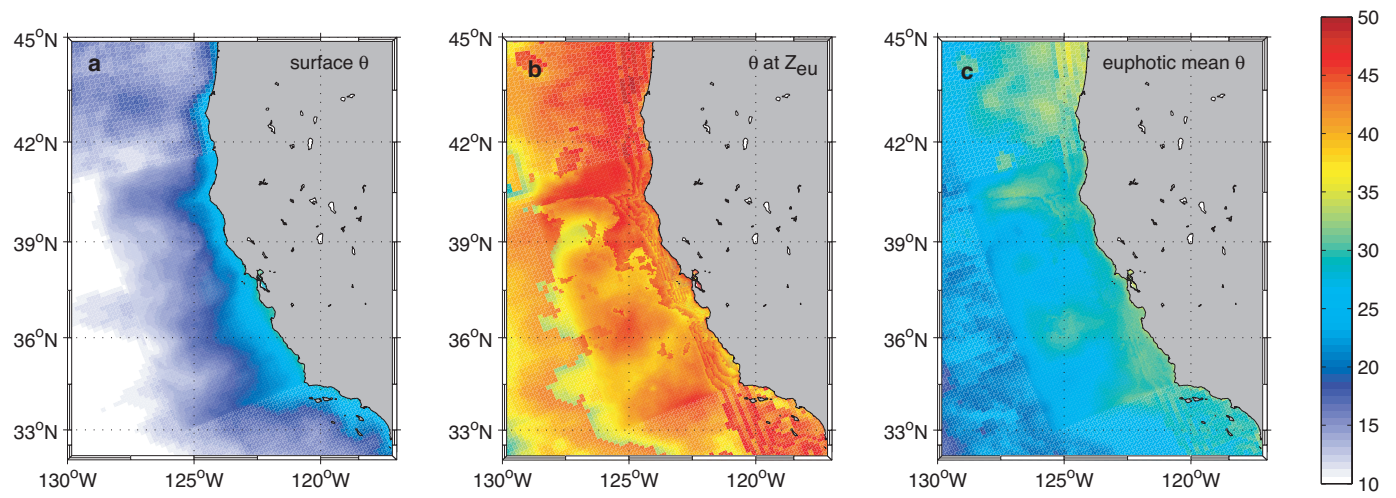

Fig. 15. Maps of the chlorophyll-to-carbon ratio, $\theta$ in units of $\mu \mathrm{g}$ Chl-a $(\mathrm{mg} \mathrm{C})^{-1}$. (a) Surface $\theta$, (b) $\theta$ at the bottom of the euphotic zone, and (c) euphotic zone mean $\theta$. The euphotic zone mean $\theta$ has been calculated from the euphotic mean Chl-a and phytoplankton biomass. 

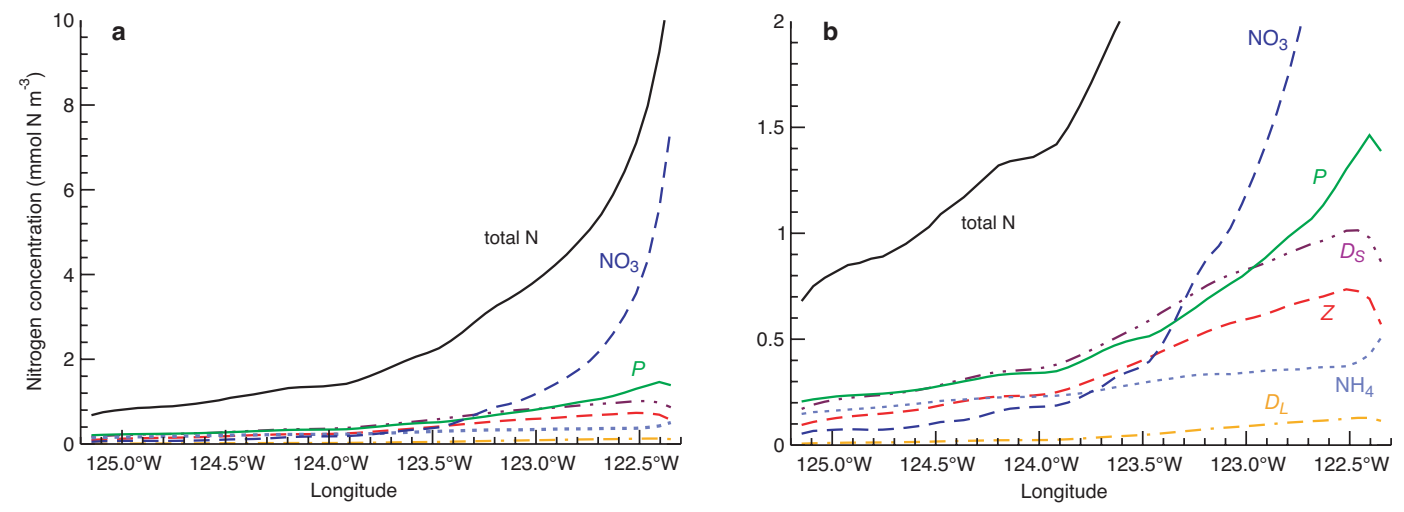

Fig. 16. Annual mean surface concentrations of nitrogen bearing ecosystem variables as a function of longitude (offshore distance) for the central California upwelling region. Variables have been averaged meridionally over $50 \mathrm{~km}$ centered at $36.4^{\circ} \mathrm{N}$ at the coast line. Panel (a) shows the variables over the entire range of the ordinate, while panel (b) focuses on the lower range.
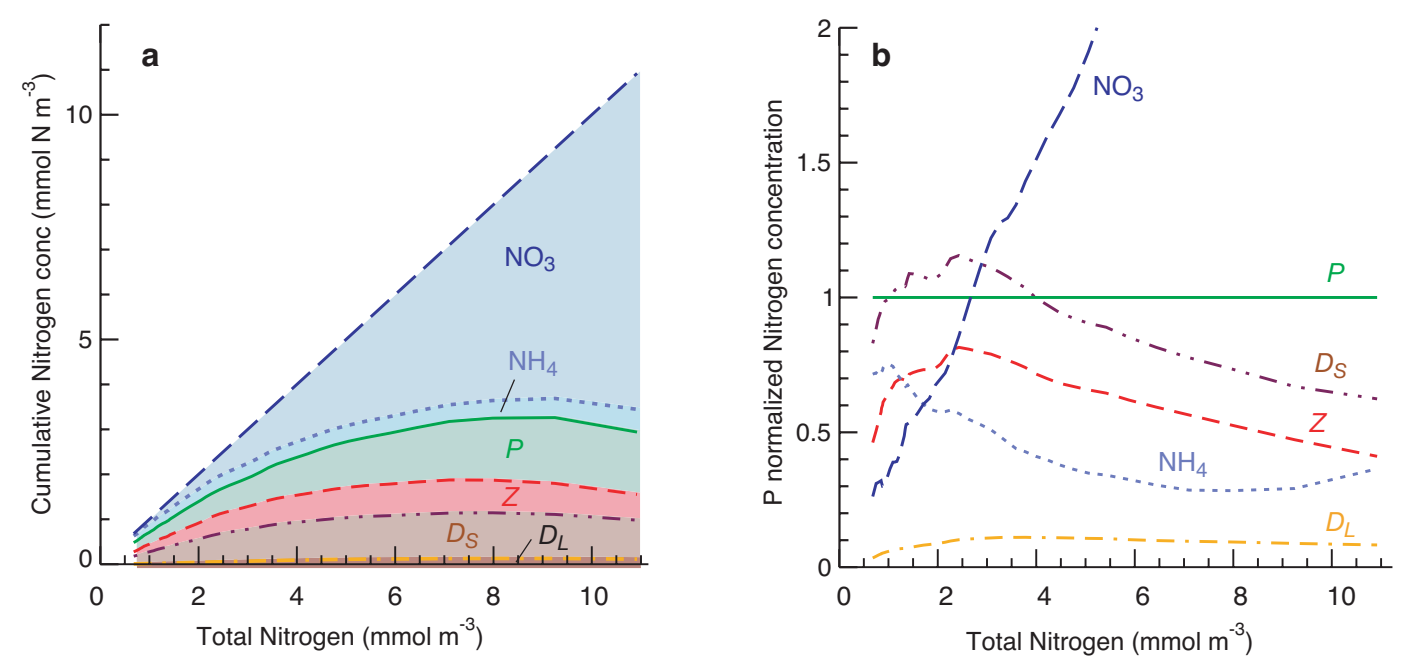

Fig. 17. Plots of nitrogen allocation in the near surface ocean ecosystem. Plotted are the annual mean concentrations shown in Figure 16 as a function of the total nitrogen content of the ecosystem. Panel (a) shows a cumulative plot, while panel (b) depicts the concentrations after normalization to the phytoplankton concentration. 

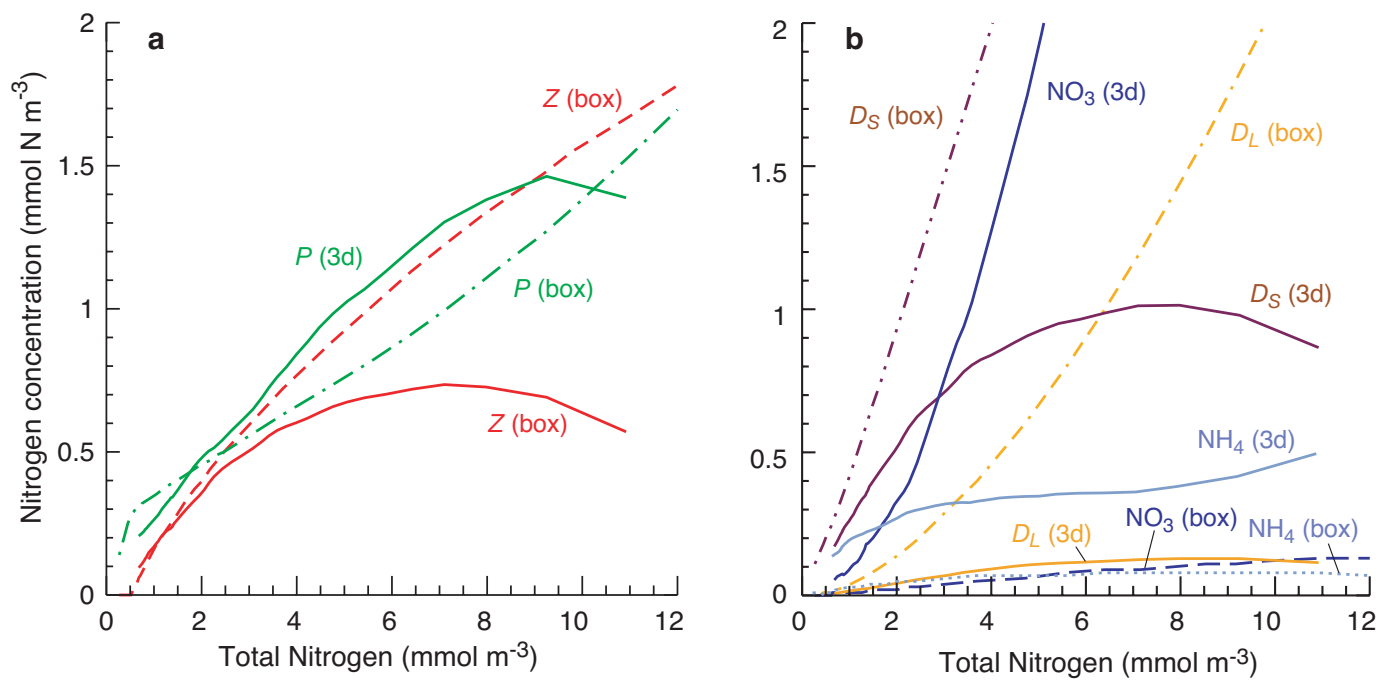

Fig. 18. Comparison of nitrogen allocation in the ecosystem between the 3-D simulations and a box model solution as a function of total ecosystem nitrogen content. (a) Results for phytoplankton $(P)$ and zooplankton $(Z)$; (b) results for nitrate $\left(\mathrm{NO}_{3}\right)$, ammonium $\left(\mathrm{NH}_{4}\right)$, and the two detrital pools $\left(D_{L}\right.$ and $\left.D_{S}\right)$. The 3 -D solutions are the annual mean results for the central California upwelling system shown in Figure 16. The box model solutions were computed by implementing the ecosystem in a box model configuration of the upper-ocean mixed layer, and then by running it to steady-state for various levels of nitrate input (see text for details). 

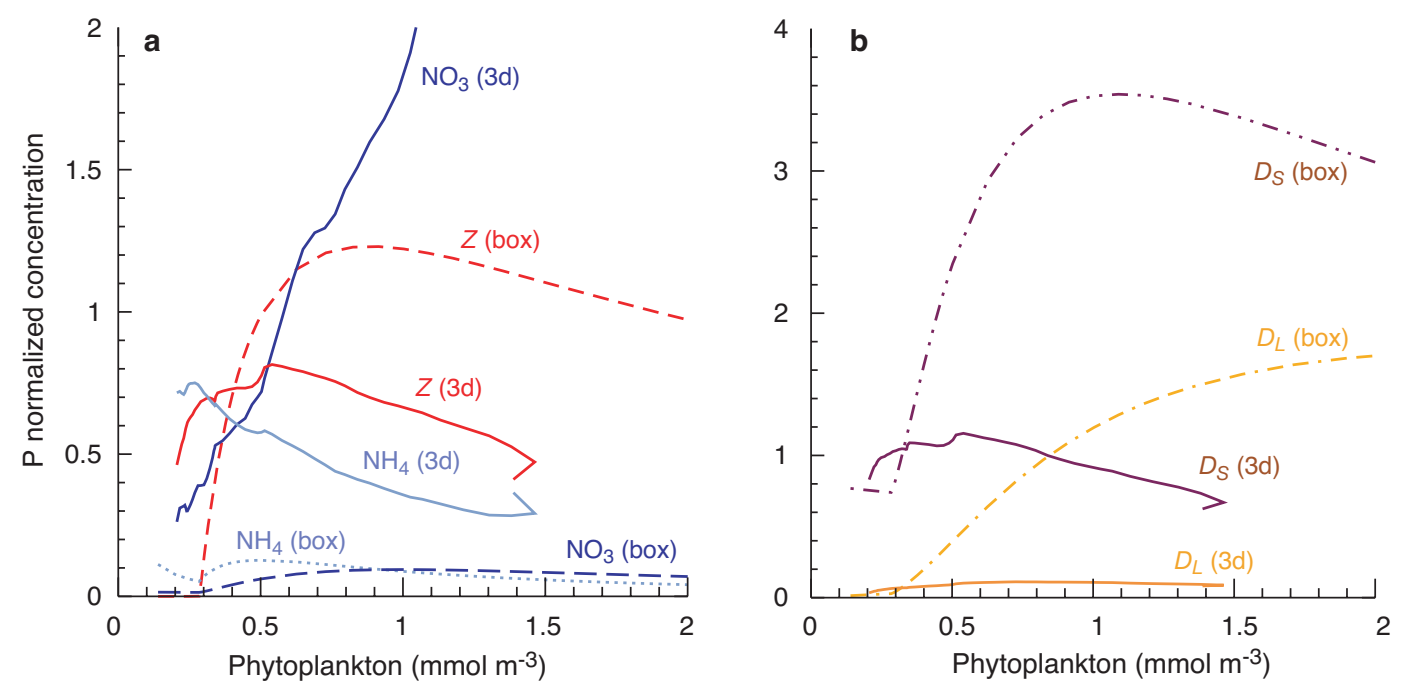

Fig. 19. Comparison of the nitrogen allocation relative to phytoplankton abundance between the 3-D simulations and a box model. (a) Comparison for zooplankton $(Z)$, nitrate $\left(\mathrm{NO}_{3}^{-}\right)$, and ammonium $\left(\mathrm{NH}_{4}^{+}\right)$; (b) comparison for small $\left(D_{S}\right)$ and large detritus $\left(D_{L}\right)$. Note different scaling of the ordinate in (b). 
Table 1

Values, units, and definitions for the parameters of the ecological-biogeochemical

$\underline{\text { model }}$

\begin{tabular}{|c|c|c|c|}
\hline Parameter & Symbol & Value & Units \\
\hline \multicolumn{4}{|c|}{ Phytoplankton Parameters } \\
\hline Half-sat. conc. for nitrate uptake & $K_{N_{n}}$ & 0.75 & $\mathrm{mmol} \mathrm{m}^{-3}$ \\
\hline Half-sat. conc. for ammonium uptake & $K_{N_{r}}$ & 0.50 & $\mathrm{mmol} \mathrm{m}{ }^{-3}$ \\
\hline Phytoplankton linear mortality rate & $\eta_{P}^{m o r t}$ & 0.024 & day $^{-1}$ \\
\hline Initial slope of P vs I relationship & $\alpha_{P}$ & 1.0 & mg C (mg Chl-a $\mathrm{W} \mathrm{m}^{-2}$ day $)^{-1}$ \\
\hline Max. chlorophyll-to-carbon ratio & $\theta^{\max }$ & 0.0535 & mg Chl-a $(\operatorname{mg~C})^{-1}$ \\
\hline \multicolumn{4}{|c|}{ Zooplankton Parameters } \\
\hline Zooplankton grazing rate & $g_{Z}^{g r a z}$ & 0.6 & day $^{-1}$ \\
\hline Zooplankton assimilation efficiency & $\beta_{Z}^{\text {assim }}$ & 0.75 & - \\
\hline Z.plankt. grazing half-sat. conc. for $P$ & $K_{P}$ & 1.0 & $\mathrm{mmol} \mathrm{N} \mathrm{m}^{-3}$ \\
\hline Zooplankton quadratic mortality rate & $\eta_{Z}^{m o r t}$ & 0.1 & day $^{-1}\left(\mathrm{mmol} \mathrm{m}^{-3}\right)^{-1}$ \\
\hline Zooplankton basal metabolism rate & $\eta_{Z}^{m e t a b}$ & 0.1 & day $^{-1}$ \\
\hline Zooplankton mortality alloc. fract. & $\Omega_{Z}^{\text {mort }}$ & 0.33 & - \\
\hline Zooplankton egestion alloc. fract. & $\Omega_{Z}^{\text {egest }}$ & 0.33 & - \\
\hline \multicolumn{4}{|c|}{ Remineralization and Coagulation Parameters } \\
\hline Nitrification rate in the dark & $k^{n i t r, \max }$ & 0.05 & day $^{-1}$ \\
\hline Nitrification inhibition threshold $I$ & $I_{N_{r}}^{t h}$ & 0.0095 & $\mathrm{~W} \mathrm{~m}^{-2}$ \\
\hline Nitrification inhibition half-dose $I$ & $I_{N_{r}}^{h d}$ & 0.036 & $\mathrm{~W} \mathrm{~m}^{-2}$ \\
\hline Particle coagulation rate & $k^{\text {coag }}$ & 0.005 & day $^{-1}\left(\mathrm{mmol} \mathrm{m}^{-3}\right)^{-1}$ \\
\hline Remineralization rate of $D_{S}$ & $k_{D_{S}}^{r e m i n}$ & 0.03 & day $^{-1}$ \\
\hline Remineralization rate of $D_{L}$ & $k_{D_{L}}^{r e m i n}$ & 0.01 & day $^{-1}$ \\
\hline Remineralization rate of $S_{D}$ & $k_{S_{D}}^{r e m i n}$ & 0.003 & day $^{-1}$ \\
\hline \multicolumn{4}{|c|}{ Sinking Parameters } \\
\hline Sinking velocity of $P$ & $w_{P}^{\operatorname{sink}}$ & 0.5 & $\mathrm{~m} \mathrm{day}^{-1}$ \\
\hline Sinking velocity of $D_{S}$ & $w_{D_{S}}^{\operatorname{sink}}$ & 1.0 & $\mathrm{~m} \mathrm{day}^{-1}$ \\
\hline Sinking velocity of $D_{L}$ & $w_{D_{L}}^{\operatorname{sink}}$ & 10 & $\mathrm{~m} \mathrm{day}^{-1}$ \\
\hline \multicolumn{4}{|c|}{ Optical Parameters } \\
\hline Light attenuation coeff. for seawater & $\kappa_{s w}$ & 0.04 & $\mathrm{~m}^{-1}$ \\
\hline Chl-a specific light attenuation coeff. & $\kappa_{\text {chla }}$ & 0.024 & $\mathrm{~m}^{-1}\left(\mathrm{mg} \text { Chl-a } \mathrm{m}^{-3}\right)^{-1}$ \\
\hline
\end{tabular}

